\title{
Estimate of size distribution of charged MSPs measured in situ in winter during the WADIS-2 sounding rocket campaign
}

\author{
Heiner Asmus ${ }^{1}$, Tristan Staszak ${ }^{1}$, Boris Strelnikov ${ }^{1}$, Franz-Josef Lübken ${ }^{1}$, Martin Friedrich ${ }^{2}$, and Markus Rapp ${ }^{3,4}$ \\ ${ }^{1}$ Leibniz Institute of Atmospheric Physics, Kühlungsborn, Germany \\ ${ }^{2}$ Graz University of Technology, Graz, Austria \\ ${ }^{3}$ Deutsches Zentrum für Luft- und Raumfahrt, Institut für Physik der Atmosphäre, Oberpfaffenhofen, Germany \\ ${ }^{4}$ Meteorologisches Institut München, Ludwig-Maximilians-Universität München, Munich, Germany \\ Correspondence to: Heiner Asmus (asmus@iap-kborn.de)
}

Received: 16 May 2017 - Revised: 17 July 2017 - Accepted: 19 July 2017 - Published: 24 August 2017

\begin{abstract}
We present results of in situ measurements of mesosphere-lower thermosphere dusty-plasma densities including electrons, positive ions and charged aerosols conducted during the WADIS- 2 sounding rocket campaign. The neutral air density was also measured, allowing for robust derivation of turbulence energy dissipation rates. A unique feature of these measurements is that they were done in a true common volume and with high spatial resolution. This allows for a reliable derivation of mean sizes and a size distribution function for the charged meteor smoke particles (MSPs). The mean particle radius derived from Schmidt numbers obtained from electron density fluctuations was $\sim 0.56 \mathrm{~nm}$. We assumed a lognormal size distribution of the charged meteor smoke particles and derived the distribution width of 1.66 based on in situ-measured densities of different plasma constituents. We found that layers of enhanced meteor smoke particles' density measured by the particle detector coincide with enhanced Schmidt numbers obtained from the electron and neutral density fluctuations. Thus, we found that large particles with sizes $>1 \mathrm{~nm}$ were stratified in layers of $\sim 1 \mathrm{~km}$ thickness and lying some kilometers apart from each other.
\end{abstract}

Keywords. Atmospheric composition and structure (middle atmosphere - composition and chemistry)

\section{Introduction}

The Earth's mesosphere and lower thermosphere (MLT) region is a natural laboratory for dusty-plasma physics. The dust in this region is thought to have its origin in recondensed material from ablated meteoroids (e.g., Rosinski and Snow, 1961; Hunten et al., 1980; Megner et al., 2006; Vondrak et al., 2008; Plane et al., 2014, 2015). The existence of these so-called meteor smoke particles (MSPs) has been mainly shown by rocket-borne measurements (e.g., Gelinas et al., 1998; Lynch, 2005; Rapp et al., 2005, 2008, 2011; Robertson et al., 2014). In addition, indirect remote sensing techniques such as incoherent scatter radars and satellite-based measurements have been used to study MSP properties (Rapp et al., 2007; Strelnikova et al., 2007; Fentzke et al., 2009; Hervig et al., 2009). It has been shown that MSPs are important for the D-region charge balance (Friedrich et al., 2011, 2012; Baumann et al., 2013, 2015; Robertson et al., 2014; Asmus et al., 2015). Moving with the background flow and bound to neutral air turbulence, charged MSPs are also suggested to be potentially involved in the formation of so-called polar mesospheric winter echoes (PMWEs) (e.g., Kavanagh et al., 2006; Lübken et al., 2007; Kero et al., 2008; La Hoz and Havnes, 2008; Havnes and Kassa, 2009; Havnes et al., 2011; Strelnikova and Rapp, 2013; Stebel et al., 2004; Belova et al., 2008). There are also theories explaining the formation of PMWEs by neutral turbulence and an increased electron density (e.g., Lübken et al., 2006). Moreover, even a connection to infrasound has been suggested (Kirkwood et al., 2006). Nevertheless, the role of heavy charged particles in the formation process of PMWEs is still under discussion. Microphysical properties such as charge state, charge densities and size distributions are indispensable for the investigation of the relevance of MSPs for the physics of the MLT region. A large effort has been made in this field in recent years. The charge state and the number of MSPs, for example, were 
extensively studied by Rapp et al. (2010), who stated that MSPs are most probably positively charged during daytime (sunlit conditions) and are negatively charged during nighttime (darkness). This was shown later by size- and chargedependent measurements made by Robertson et al. (2014) additionally showing that there can be very large differences between the number of particles of a given size. In the present work we use results of rocket-borne measurements to obtain the number of charged particles, mean particle size and an estimate of charged particle size distribution.

This paper shows results of experimental investigation of MSPs in the frame of the WADIS sounding rocket mission and is structured as follows. Section 2 gives a short overview of the rocket campaign and the rocket instrumentation. Here we also present details of the particle detector used to measure heavy charged aerosols. In Sects. 3 and 4 the results of charged particle measurements, electron density fluctuations and a charged particle size distribution are presented and discussed in Sect. 5. Finally, we summarize our findings in Sect. 6.

\section{Experiment description}

The WADIS sounding rocket project lead by the Leibniz Institute of Atmospheric Physics (IAP) in Kühlungsborn, Germany, with contributions from Austria, Sweden, the USA and Norway comprised two field campaigns conducted from the Andøya Space Center (ACS) in northern Norway $\left(69^{\circ} \mathrm{N}, 16^{\circ} \mathrm{E}\right)$. The second campaign was conducted in March 2015 and the instrumented sounding rocket was launched on 5 March, at 01:44:00 UT, when MLT thermal structure and circulation regime were in a pure winter state. The name WADIS stands for "Wave propagation and dissipation in the middle atmosphere: Energy budget and distribution of trace constituents". The main goal of the mission was to study propagation of gravity waves (GWs) from their sources in the troposphere to their level of dissipation in the MLT and quantification of their contribution to the energy budget of the MLT. For an overview of the WADIS project and its main mission the reader is referred to Strelnikov et al. (2017).

The WADIS payloads were equipped with instruments to measure temperature and density of the neutral atmosphere, neutral air turbulence and densities of all plasma species, including positive ions, electrons and charged MSPs. A unique feature of the WADIS experiment was that both neutral atmospheric and plasma densities were measured simultaneously in the same volume during upleg-facing ram. This allows us to make a reliable estimate of some MSP properties derived and discussed in this work. Moreover, the mesosphere was also monitored by ground-based instruments, in particular the Middle Atmosphere Alomar Radar System (MAARSY) (Latteck et al., 2012; Rapp et al., 2011). MAARSY observed no echoes during the day of the rocket launch.

\subsection{Payload instrumentation}

Figure 1 shows the WADIS payload with the instrumentation. Both the front and rear decks of the payload were equipped with identical CONE (COmbined sensor for Neutrals and Electrons) instruments to measure turbulence, neutral air temperature and density, and electron density with very high spatial resolution on the order of approximately centimeters (Giebeler et al., 1993). These measurements allow investigation of small-scale structures in both species (neutrals and electrons) at spatial scales from several kilometers down to tens of centimeters along the rocket trajectory. CONE combines an ionization gauge with a fixed biased probe for electron density measurements. For a detailed description of the CONE instrument the reader is referred to Giebeler et al. (1993) and Strelnikov et al. (2013).

The positive ion probe (PIP) mounted on the rear deck of the WADIS payload and operated by University of Technology in Graz (TUG) yields measurements of ion densities with spatial resolution down to meter scales (see, e.g., Folkestad, 1970; Blix et al., 1990).

Both the electron probe of the CONE instrument and PIP are electrostatic probes, meaning that they are fixed biased at +3 and $-6 \mathrm{~V}$ relative to rocket skin potential. The payload is charged until the sum of currents onto the payload surface is zero. The equilibrium potential is the floating potential of the surrounding plasma and is usually on the order of $-2 \mathrm{~V}$ (Bekkeng et al., 2013). Therefore, the measured currents are proportional to the local density of the respective plasma species. It is assumed that the payload potential changes slowly compared to changes in ionospheric densities along the rocket path. Since the payload potential is the reference to all electrostatic probes, the probes yield relative density measurements. Moreover, the impact of changing payload potential onto particle detection is small since it scales with particle kinetic energy. The change in the payload potential is usually on the order of a couple of volts, whereas the particles greater $\sim 0.7 \mathrm{~nm}$ have larger kinetic energies of 10 to hundreds of electron volts (Bekkeng et al., 2013). A change in payload potential by $2 \mathrm{~V}$ increases the critical detectable radius due to electrostatic barrier by only approximately $0.2 \mathrm{~nm}$, i.e., from 0.6 to $0.8 \mathrm{~nm}$.

The wave propagation experiment (also often referred to as Faraday) operated by TUG yields absolute electron density measurements but with a limited height resolution of $\approx 1 \mathrm{~km}$ (e.g., Bennett et al., 1972; Jacobsen and Friedrich, 1979). This technique is independent of the payload potential and is used, for example, for normalization of the relative density measurements by electrostatic probes (e.g., Friedrich et al., 2012, 2013).

The two IAP particle detectors (PD 1 and PD 2) symmetrically mounted off the symmetry axis on the front deck of the payload yield measurements of heavy charged particles with altitude resolution on the scale of meters. The front deck was exposed to the atmosphere after the nose cone ejection at $52 \mathrm{~s}$ 
FWD

AFT

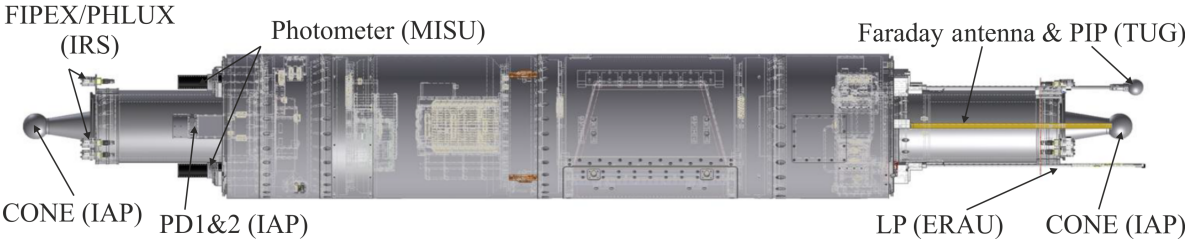

Figure 1. WADIS 2 payload configuration with its instruments (corresponding institution abbreviation): CONE (IAP), FIPEX/PHLUX (IRS), two PDs (IAP) and two photometers (MISU) on the forward deck (FWD) and a wave propagation experiment/Faraday antennas, PIP (both TUG), LP (ERAU) and CONE on the aft deck (AFT).

after lift-off at an altitude of $63 \mathrm{~km}$. In the next section we describe the PD in more detail.

\subsection{Particle detector}

The particle detector (PD) is a Faraday cup first applied for rocket-borne aerosol measurements in the MLT by Havnes et al. (1996) and repeatedly used by other studies (e.g., Gelinas et al., 1998; Lynch, 2005; Rapp et al., 2005, 2011). It consists of an electrode shielded from the ambient plasma by two grids and placed in a metal cup. A detailed description of the instrument can be found in Asmus et al. (2013). The grids of the WADIS-PD were biased at +6.2 and $-6.2 \mathrm{~V}$ for the outer and inner grid, respectively. Therefore, they repelled positive ions and electrons, respectively. The grids had identical transparencies of 0.74 , which means that, without considering aerodynamic and electrostatic barriers, a maximum of $55 \%\left(0.74^{2}\right)$ of the incident particles were able to penetrate to the inner electrode. The electrode and both grids were connected to sensitive linear electrometers. Thus, the inner electrode yielded measurements of the net charge density of the heavy species. The measurement range for the inner electrode was from $4 \mathrm{pA}$ to $20 \mathrm{nA}$. All currents were sampled with 16 bit resolution at $1 \mathrm{kHz}$. The measured current is proportional to the rocket velocity and the charge number density of the dust. For a typical rocket velocity of $\sim 1000 \mathrm{~m} \mathrm{~s}^{-1}$ this yields a theoretical altitude resolution of $1 \mathrm{~m}$. Charged particles hitting the PD electrode deposit their charge, which is measured as a current. This resulting current is clearly the sum of positive and negative charges.

\subsubsection{Data reduction}

Following Havnes et al. (1996) the MSP charge density, $N_{\mathrm{d}} Z_{\mathrm{d}}$, can be derived as

$N_{\mathrm{d}} Z_{\mathrm{d}}=\frac{I_{\mathrm{s}}}{e \cdot v_{\mathrm{R}} \cdot A_{\mathrm{s}} \cdot(1-\sigma)^{2}}$,

where $I_{\mathrm{S}}$ is the current measured by the sensor's electrode, $e$ is the elementary charge, $v_{\mathrm{R}}$ is the rocket velocity, $A_{\mathrm{S}}=19.75 \mathrm{~cm}^{2}$ is the sensor electrode's area and $(1-\sigma)=$ 0.74 is the transparency of a grid. Note that this simplified expression does not account for secondary charging effects inside the instrument (e.g., Havnes et al., 1996; Kassa et al., 2012; Asmus et al., 2013). Direct electron secondary emission does not play a role at velocities of $\leq 1000 \mathrm{~m} \mathrm{~s}^{-1}$ (Dalmann et al., 1977; Havnes and Næsheim, 2007). The main charging effect for lower velocities $\left(\leq 1000 \mathrm{~m} \mathrm{~s}^{-1}\right)$ is thought to have its origin from particles impacting on a surface at a relatively large incident angle relative to the surface zenith and carry away electrons or ions leaving the surface. However, we neglect this effect since the majority of particle trajectories are at a right angle to the surface of the electrode as well as to the grids whose wires are rectangular since coning angle of the WADIS- 2 flight did not exceed $3^{\circ}$. The inner grid was also connected to an electrometer to enable the assessment of secondary charging effects. However, these measurement (not shown here) appeared to be very noisy with no prominent signature indicating the influence of the secondary effects on the prime measurements. Additionally, in Eq. (1) we neglect that particles that already passed the primary shock front might move with a lower velocity than $v_{\mathrm{R}}$ when entering the Faraday cup.

\subsubsection{Combined aerodynamic and electrostatic simulations}

Due to the supersonic velocity of the sounding rocket a shock front is formed in front of the payload. This shock wave influences the in situ measurements. Fortunately, supersonic freemolecular flow and thus shock fronts can be well simulated for sounding rockets (e.g., Gumbel, 2001; Rapp and Lübken, 2001; Hedin et al., 2007; Plane et al., 2014; Staszak, 2015). The standard tool widely used for sounding rockets is the direct simulations Monte Carlo (DSMC) technique developed by Bird (1994). The DSMC algorithm is implemented in different simulation packages and can be combined, for example, with the electrostatic simulations by the ion optics simulation tool SIMION ${ }^{\circledR}$ (Scientific Instrument Services, 2013) to obtain particle trajectories in non-vacuum conditions.

We performed simulations in 2-D for a cross section of the forward instrument deck of the WADIS-2 payload. Using axial symmetry we simulated just half of the deck. To assess the particles sizes passing through the primary shock 

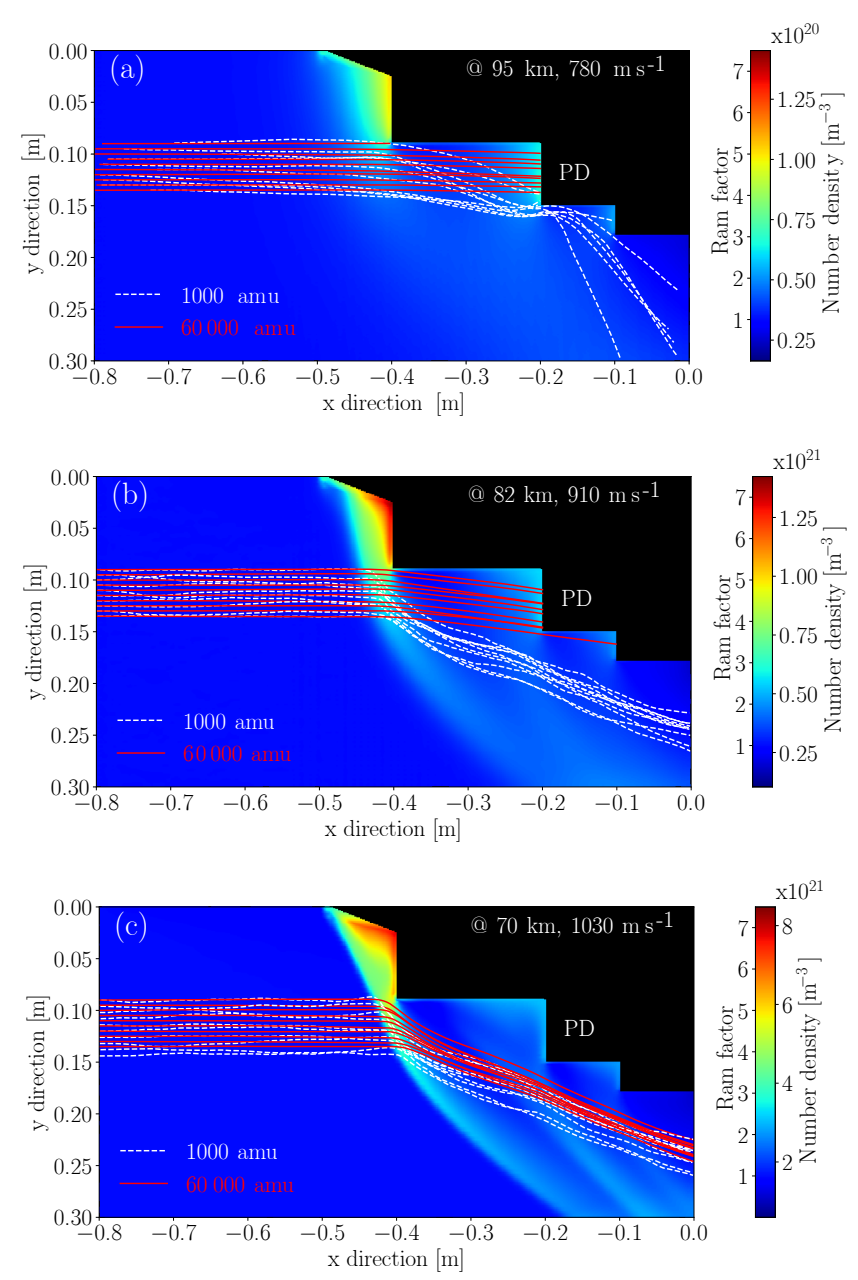

Figure 2. Results of combined DSMC and electrostatic simulations for WADIS-2 payload. The black area shows one half of the WADIS- 2 front deck. $X$ axis is along the rocket's roll axis. The position of the particle detector is indicated with PD. Density field derived using the DSMC for 95,82 and $70 \mathrm{~km}$. White and red lines correspond to trajectories of particles with 1000 and $60000 \mathrm{amu}$, respectively. The upstream flow is from left.

front and reaching the PDs outer grid, i.e., the cup's inlet, four heights within the measurement altitude range of the PD were simulated, i.e., for 70, 75, 82 and $95 \mathrm{~km}$. The background atmosphere and the flight conditions for simulations were taken from actual measurements during the WADIS-2 flight. Results of these simulations $(70,82$ and $95 \mathrm{~km})$ are demonstrated in Fig. 2, showing particle trajectories (solid lines) and the density fields obtained from DSMC. Note that the PD grids and the cups inside are not resolved in this 2-D simulation. The PD inlet (the outer grid) is represented by a biased electrode with zero transparency.

Indicated by increased density, the main shock front is formed in front of the CONE instrument from -0.5 to $-0.4 \mathrm{~m}$ in the $x$ direction with ram factors, i.e., the ratio of undisturbed ambient density to the density inside the mea-

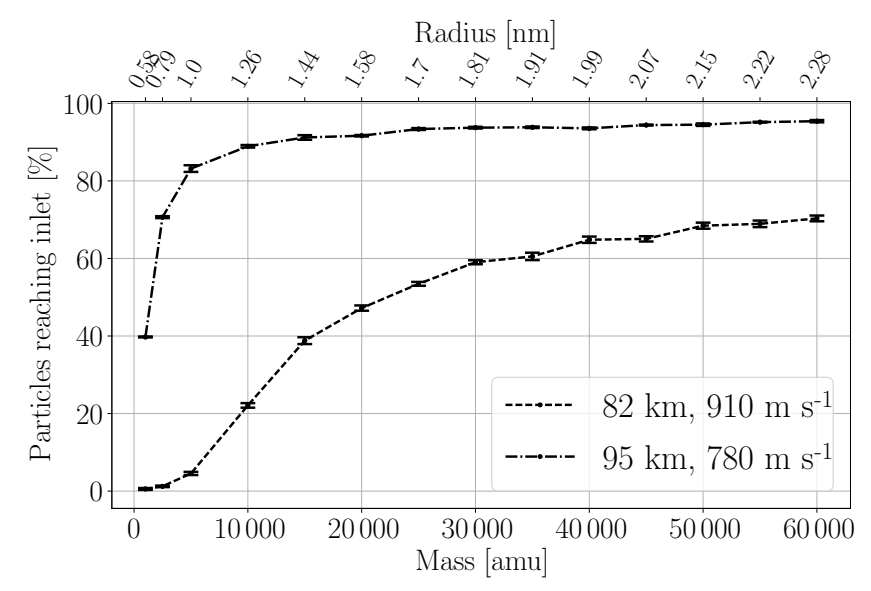

Figure 3. Simulated probabilities that particles reach the PD inlet (outer grid) as a function of mass (radius) for 82 and $95 \mathrm{~km}$. The velocity and background atmosphere correspond to WADIS-2 flight conditions. The statistics was derived from 4000 particle trajectories keeping the statistical error $<1 \%$.

surement volume, between 3.5 and 6 near the payload body. It is apparent that, at $70 \mathrm{~km}$ height (Fig. 2c), the aerodynamics prohibit dust measurements even for large particles with masses of $60000 \mathrm{amu}$, which corresponds to radii of approximately $2.3 \mathrm{~nm}$. It is also seen that light particles are "blown" away from PD by the shock front (white lines). This loweraltitude limit for Faraday cups was also found earlier by, for example, Horányi et al. (1999), Hedin et al. (2007), and Strelnikova et al. (2009).

Note that these simulations have a probabilistic character, which implies that number of trajectories should be calculated to get appropriate statistics. This has been done for 4000 particles and the derived probabilities are summarized in Fig. 3. The $y$ axis in Fig. 3 shows probability in percent that the MSP reaches the PD. The dashed and the dotted lines show results for 82 and $95 \mathrm{~km}$ height, respectively. It is apparent by comparing those two heights that particles reach the PD much more efficiently at $95 \mathrm{~km}$ than at $82 \mathrm{~km}$. This is true for all particle radii which were simulated. The difference becomes larger for smaller radii. Particles with radii less than $\sim 0.8 \mathrm{~nm}$ cannot reach the PD at $82 \mathrm{~km}$, whereas $40 \%$ of the $0.6 \mathrm{~nm}$ particles reach the PD at $95 \mathrm{~km}$. At $75 \mathrm{~km}$ altitude and lower only MSPs with radii $\gtrsim 2.3 \mathrm{~nm}$, i.e., $\gtrsim 60000 \mathrm{amu}$, can reach the PD, which is beyond the plot range in Fig. 3.

Charged particles are influenced by electrostatic forces. Therefore, the detectable size distribution is also limited by the electrostatic potentials at the shielding grids. If one assumes that the potential in the grids plane is uniform, a first guess of the mass of the particles that are able to reach the PD's electrode can be derived from the energy conservation law: $\frac{m}{2} v_{\mathrm{R}}^{2}=e U$, where $U$ is the grid bias of $6.2 \mathrm{~V}, e$ is the elementary charge, $v_{\mathrm{R}}$ is the rocket (particle) velocity and $m=\frac{4}{3} \pi \varrho r^{3}$ is mass of the MSP. This gives the critical radius 


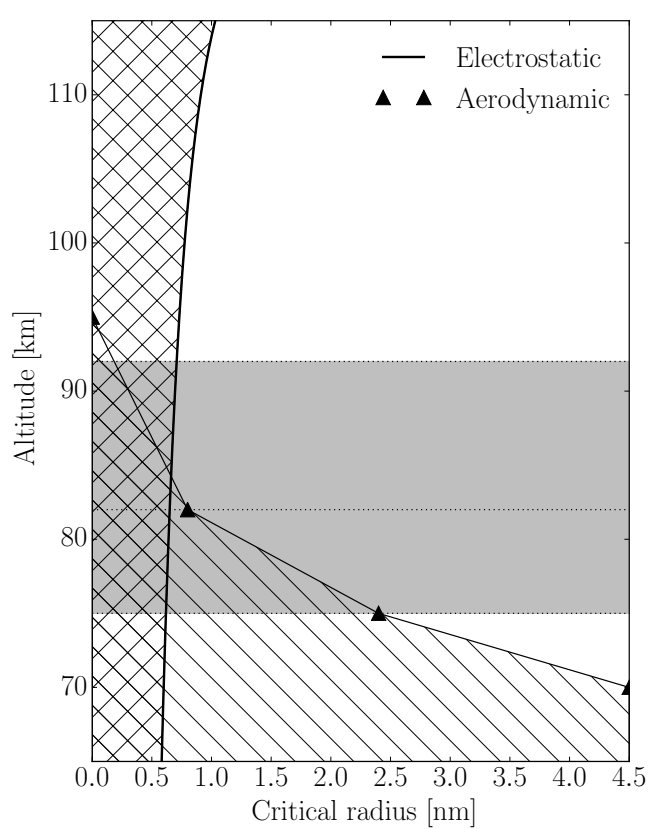

Figure 4. Minimum critical radius due to electrostatic filtering $E_{\text {kin }}=\frac{m}{2} v^{2}=e U$ for vacuum conditions (solid black line) and from aerodynamic simulations (black triangles). The aerodynamic critical radius is the minimum size where the detection probability is larger than zero. The hatchings indicate which particle size cannot be detected. The grey shaded area marks the altitude range of the measured dust layer. The dashed line at $82 \mathrm{~km}$ indicates the layer peak height.

of the MSP due to electrostatic barrier:

$r=\sqrt[3]{\frac{3 e U}{2 \pi \varrho v_{\mathrm{R}}^{2}}}$,

where $\varrho=2 \mathrm{~g} \mathrm{~cm}^{-3}$ is the assumed MSP mass density (Robertson et al., 2014; Plane et al., 2014).

Figure 4 summarizes the combined DSMC and electrostatic simulations in terms of the critical radius as a function of altitude. Particles of radii that cannot reach the entrance (outer grid) of the PD due to either electrostatics or aerodynamics are indicated by the hatched area. The grey area indicates the altitude range of the measured negatively charged dust layer discussed in Sect. 3.2. The horizontal line at $82 \mathrm{~km}$ marks the height of the charged particle layer's peak.

The next step was to simulate the probability of particles reaching the inside of the PD, i.e. its electrode. A more detailed 3-D DSMC described by Scanlon et al. (2010) to obtain the background fields for SIMION ${ }^{\circledR}$ was used. Staszak (2015) applied the 3-D DSMC method for a complex sounding rocket instrument resolving even small grid structures down to tens of millimeters. Simulations in 3-D were necessary to consider the geometry of the PD grids and the related 3-D electric field distribution. Since these calculations are computationally expensive, only the peak height of the

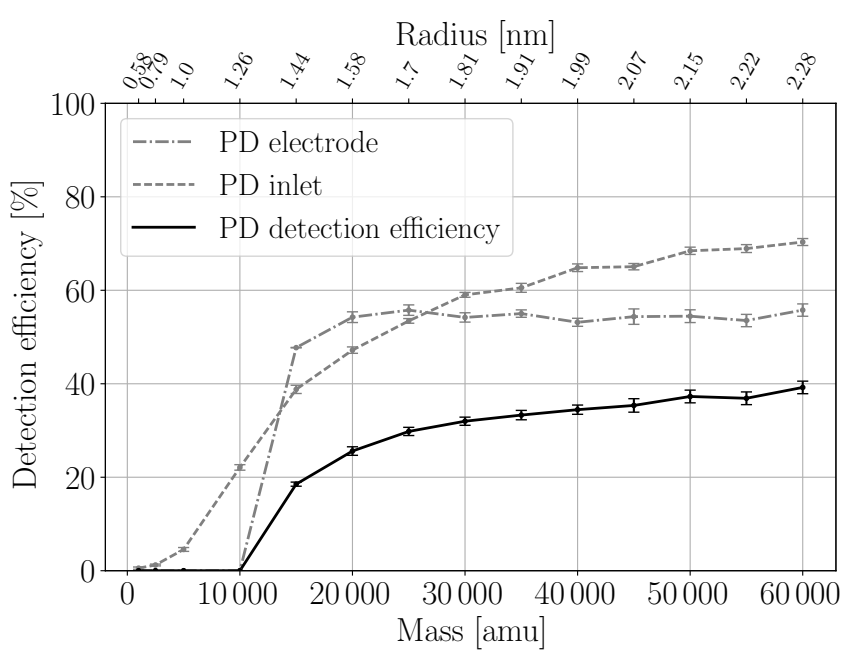

Figure 5. PD detection efficiency (black solid line) at $82 \mathrm{~km}$ as a function of particle mass (radius) by means of the product of the probabilities of particles reaching the inlet (dashed grey line, from Fig. 3) of the PD and its electrode (dashed dotted grey line) as well as the corresponding error bars. Note that uncertainties due to, for example, particle structure and payload charging are not considered. The error bars therefore only contain the statistical uncertainty of the simulation.

dust layer $(82 \mathrm{~km})$ was simulated. Also, the simulation volume was limited to the cup itself plus $20 \mathrm{~mm}$ in front of the cup's inlet. Since the simulation volume is located behind the primary shock front, all particles will be slower than their initial velocity given by the rocket velocity due to collisions with air molecules inside the shock front. The deceleration is determined by the thickness and density of the main shock front (Sternovsky, 2004).

We obtained the particle velocity from the 2-D simulation by calculating the mean velocity at $x=-0.22 \mathrm{~m}$ (see Fig. 2) from 100 particle trajectories. This was done for each particle mass. The velocity reduction is in the range of $30-40 \%$ with the deceleration being larger for smaller particles. As in the 2-D case we now can simulate particle trajectories in 3 -D and count the number of particles reaching the electrode of the PD. The maximum percentage of particles reaching the electrode is $\sim 55 \%$ due to the grid's mechanical transparency $\left(\operatorname{Tr}=0.74^{2}=0.55\right)$, which is well reproduced by the simulations (see Fig. 5, dashed dotted curve "PD electrode"). The product of the probability of particles reaching the inlet of the PD obtained from the 2-D simulation with the probability of particles reaching the electrode obtained from the 3-D simulation gives us the final estimated detection efficiency of the instrument at $82 \mathrm{~km}$ (see Fig. 5). Note that Fig. 5 only shows the statistical errors derived from the simulations and does not include the uncertainties introduced by, for example, unknown particle structure or influences of payload charging. Particles larger than $\sim 15000 \mathrm{amu}$ can be efficiently detected, whereas smaller particles are filtered by 
aerodynamics and electrostatics. The critical radius at $82 \mathrm{~km}$ is $\sim 1.3 \mathrm{~nm}$, which is approximately 2 times larger compared to the particle size able to reach the PD inlet obtained the 2-D simulation shown in Fig. 4. This is due to the fact that electrostatics are combined with aerodynamics and the analysis of trajectories inside the cup behind the shielding grids. The kinetic energy of the particles decreases due to deceleration by collision (from 2-D) and the critical radius due to electrostatic barrier increases (from 3-D). The results of 2-D and 3-D simulation can thus be summarized as follows:

- The 2-D simulation gives us (1) the size of particles which are transported out of the PD inflow and (2) the particle velocity in front of the PD.

- From the 3-D simulation we obtain the sizes of particles which are stopped by the shielding grids and which reach the sensor electrode.

- The combination of both gives the detection efficiency of the instrument in the WADIS-2 configuration.

\section{Measurement results}

In this section we show results of the in situ measurements of MLT dusty-plasma parameters. We start with showing the raw data measured by the PDs and describe how the MSP charge density was deduced. Then we show in situ measurements of the background plasma densities followed by analysis of small-scale structures. Finally, we will deduce a charged particle size distribution from the measured parameters.

\subsection{Raw PD data}

The analysis of raw currents for both PDs was treated in the exact same manner. We therefore show an example of the deduction of charge density for PD 1. Figure 6 shows raw current measured by the PD 1 as a grey, noisy profile.

To reduce the noise level produced by the electronics, we applied a running mean over $50 \mathrm{~ms}$. The result is shown in Fig. 6 as a green line. We found that a value of $50 \mathrm{~ms}$ gives a favorable signal-to-noise ratio. Due to their position next to the CONE instrument and off the rocket's roll axis, the currents collected by the PDs are essentially modulated by the spin frequency of the rocket. This modulation is due to aerodynamics which resulted in a periodically changing shock front ahead of the PD. Since the PDs are symmetrically mounted, this means that when one PD is in ram position the other will be in the wake. This influence is demonstrated in Fig. 7, where an altitude bin of only $1 \mathrm{~km}$ is shown. The two PDs show sinusoidal spin modulation with clear anticorrelation. When the detectors are facing the ram direction, they show maxima in the measured currents. When the PDs are in shadow, they reveal minimum values, which depend
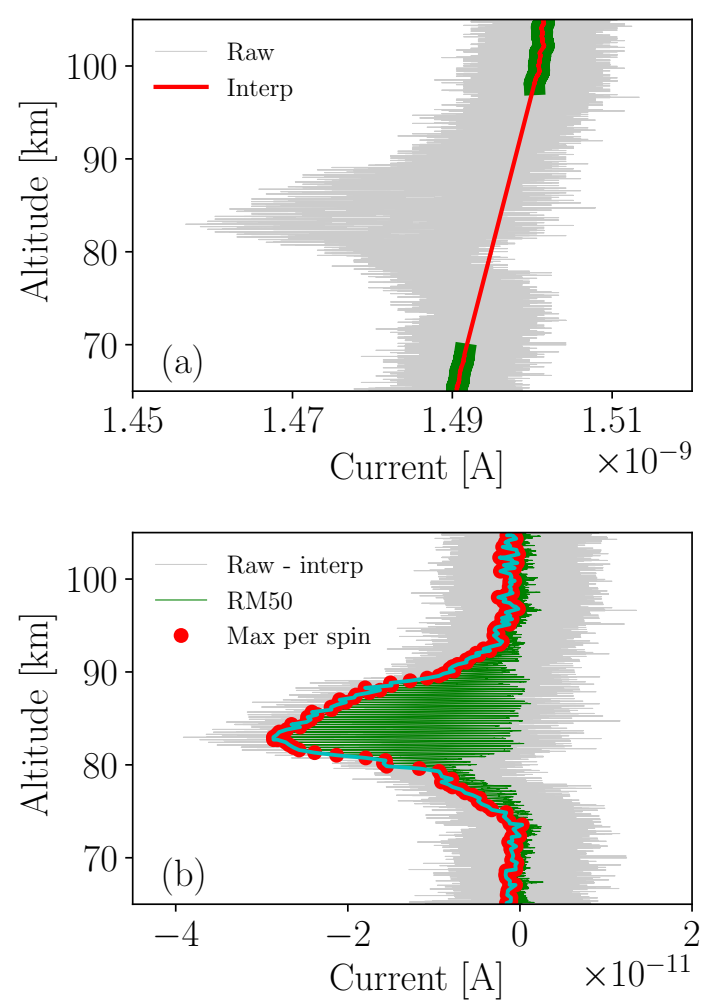

Figure 6. Conversion from raw current to charge density exemplary for PD 1. (a) Raw current (grey) and the interpolated trend (red). Green is the smoothed raw current. (b) Raw current subtracted by the interpolated trend from the upper panel. Running mean over 50 values (green) and the maximum current per spin (red dots).

on orientation of the payload relative to velocity vector of the rocket. This angle of attack was around $3^{\circ}$.

From this aerodynamical reasoning we consider the maxima of the spin-modulated currents as the most representative values for the density measurements of the charged MSPs. Thus, to derive the charge density based on Eq. (1), we pick the local maxima per spin period from the smoothed green profile. These values are shown in Fig. 6 by the red dots. Hence, the altitude resolution of the absolute density measurements by the PDs is defined by the spin rate of $3.34 \mathrm{~Hz}$, i.e., up to $\sim 300 \mathrm{~m}$.

\subsection{Background}

Figure 8 summarizes the plasma density measurements conducted in situ during the WADIS-2 sounding rocket flight. Density profiles of charged MSPs obtained from the PD measurements (see Sect. 3.1) are shown in the left panel of Fig. 8. The green and black lines represent PD 1 and PD 2 measurements, respectively. It is apparent that a pronounced negatively charged MSP layer was observed by both PDs. Altitude range and shape of the layer is almost the same in both measurements. This good agreement shows that the same layer was detected by independent instruments and gives ev- 


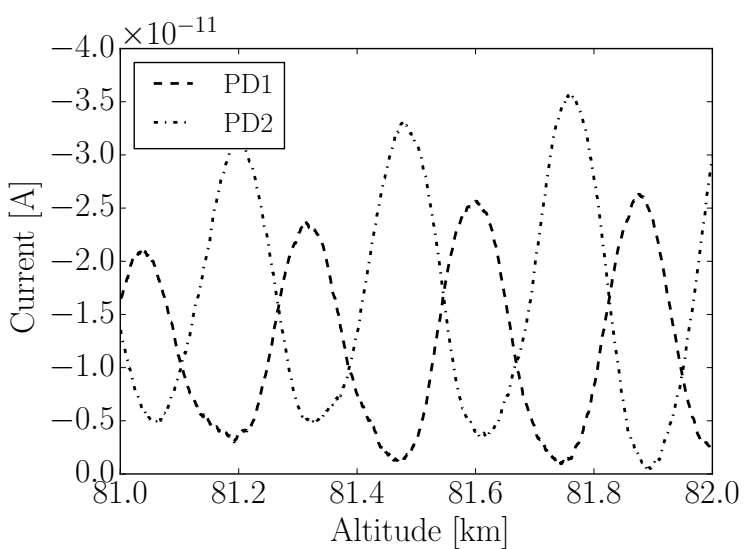

Figure 7. Smoothed PD currents (dashed: PD 1; dashed-dotted: PD 2) as a function of altitude.

idence of its existence. The current measured by the PD 1 reveals a systematic offset of 1.3 relative to the PD 2 measurements due to a lower electrometer sensitivity and the green profile is therefore scaled by this value. The peak density of negative MSPs is $-224 e \mathrm{~cm}^{-3}$ around $82 \mathrm{~km}$. As shown in Fig. 4 particle detection becomes less efficient below $\sim 82 \mathrm{~km}$. We indicate this altitude range in the left panel of Fig. 8 by using dashed lines, implying that instrumental effects become more important here.

The red profile shows absolute electron density measurements derived from the radio wave propagation technique. We recall that these measurements are not influenced by the payload charging effects and represent the best-quality absolute density values. The black profile in the right panel of Fig. 8 represents the positive ion density measurements. This profile is normalized above $104 \mathrm{~km}$ by the electron density value. Above $104 \mathrm{~km}$ the electron and positive ion densities agree very well, as expected, from the quasi-neutrality of the ionospheric plasma (not shown here). This balance between electrons and positive ions is present when other charge carriers like negative ions or charged aerosols are absent, which is the case above $\sim 100 \mathrm{~km}$ (e.g., Friedrich et al., 2012). Below $104 \mathrm{~km}$ the density profiles show an increasing discrepancy, indicating that the charge balance between electrons and positive ions is not maintained by electrons and positive ions alone. As a support to this statement, the electron density inferred from the positive ion density by neglecting charged MSPs and reactions with atomic oxygen is shown by the dashed red line in Fig. 8. This profile was obtained using (Friedrich et al., 2011, 2012)

$n_{\mathrm{e}}=\frac{n_{\mathrm{i}^{+}}}{1+\frac{\beta}{\alpha_{\mathrm{ii}}} \frac{M^{2}}{n_{\mathrm{i}^{+}}}}$,

where $n_{\mathrm{i}}^{+}$is the positive ion density, $\beta$ is the electron attachment rate, $\alpha_{\mathrm{ii}}=6 \times 10^{-8} \mathrm{~cm}^{3} \mathrm{~s}^{-1}$ is the ion-ion recombination rate and $M \simeq \mathrm{O}_{2}+\mathrm{N}_{2}$ is the background neutral density
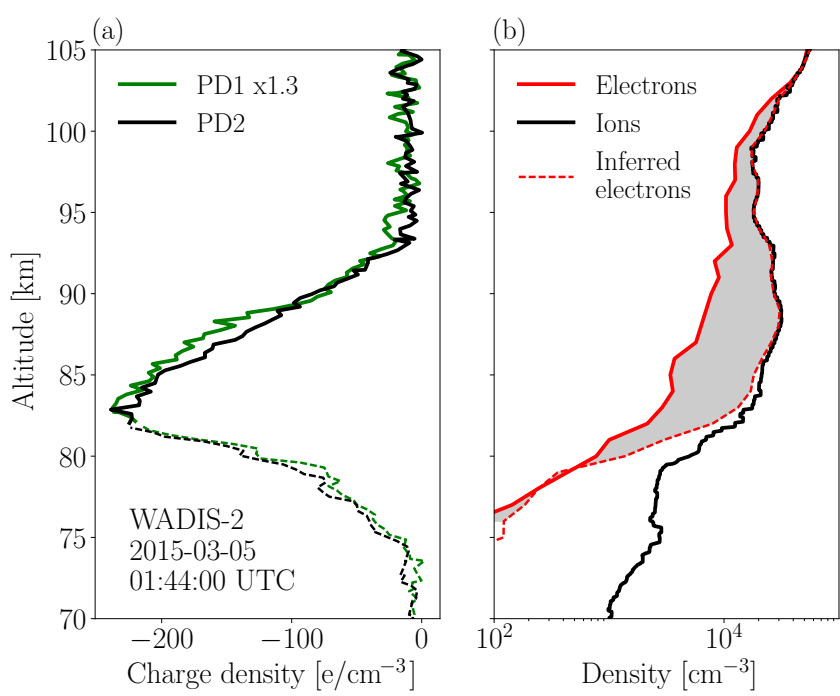

Figure 8. (a) Charged MSP profiles measured by the two PDs. The density of PD 1 (green) has been multiplied by 1.3. Dashed lines indicate the altitude range where aerodynamic effects are likely. (b) Absolute electron density (red) and positive ion density (black) measured by the wave propagation experiment and PIP, respectively. The dashed red line indicates electron density inferred from positive ion density neglecting charged MSPs and atomic oxygen reactions. The grey shaded area marks the difference between measured and inferred electron density.

(Dieminger et al., 1996). We used a ratio $\beta / \alpha_{\mathrm{ii}}=1.9 \times 10^{-31}$, which is in agreement with earlier findings by, for example, Friedrich et al. (2012). This simple approach shows that without MSPs the electron density would coincide with the positive ion density above $85 \mathrm{~km}$. However, from the measured plasma density profiles we can see that this is not the case. Thus, the difference between the measured electron density and the one derived with Eq. (3) (grey shaded area in Fig. 8) above $80 \mathrm{~km}$ is attributed to additional electron loss due to attachment to large particles such as MSPs (e.g., Rapp and Lübken, 2001; Rapp et al., 2003; Friedrich et al., 2011). Below $80 \mathrm{~km}$ the results of Eq. (3) indicate the presence of a large number of negative ions obtained by the difference between inferred electron and positive ion density. However, as the approach by Friedrich et al. (2011) does not account for destruction of negative ions by atomic oxygen and their density is most likely overestimated.

These measurements reveal that at $85 \mathrm{~km}$ there are approximately 1 order of magnitude more positive ions than electrons. The measured charge density of MSPs indicates that this discrepancy most likely is attributed to the presence of heavy negatively charged MSPs, at least between 75 and $92 \mathrm{~km}$. As described in Sect. 3.1, owing to technique limitations, the PDs were only capable of measuring a fraction of the entire population of the MSPs. Therefore, the absolute difference between ion and electron density cannot be pre- 
cisely established by the PDs. However, the measured charge density clearly shows the presence of charged MSPs.

\section{MSP size from small-scale structures}

In this Section we utilize measurements of neutral and electron densities by CONE to assess the mean radius of the observed aerosols. This estimate is based on the work by Lübken et al. (1998), who derived mean radii of ice particles inside a polar mesospheric summer echo (PMSE) layer. As mentioned in Sect. 2.1, the CONE instrument consists of two parts: an electrostatic probe to measure electron number densities and an ionization gauge to measure total density of neutral gas. These measurements are performed with very high spatial resolution and allow for investigation of smallscale structures in those species.

First, modulations of both measured time series due to the rocket's spinning motion and its harmonics were filtered using a band-stop filter. From the filtered signal we derived the relative density fluctuations, also called residuals, by subtracting a reference current:

$r_{j}(t)=\frac{I_{j}(t)-\left\langle I_{j}(t)\right\rangle}{\left\langle I_{j}(t)\right\rangle}=\frac{N_{j}(t)-\left\langle N_{j}(t)\right\rangle}{\left\langle N_{j}(t)\right\rangle}=\frac{\delta N_{j}(t)}{\left\langle N_{j}(t)\right\rangle}$,

where $I(t)$ is the measured current, $\langle I(t)\rangle$ is the reference current derived as a running mean over $2 \times 10^{4}$ data points, which corresponds to $\sim 2 \mathrm{~km}$ height range, $N$ is the density, $\langle\ldots\rangle$ denotes spatial averaging and subscripts $j=\mathrm{e}, \mathrm{n}$ refer to electrons and neutrals, respectively. Then, we apply a wavelet transform to obtain power spectra of the fluctuations (Strelnikov et al., 2003, 2009). Here we use a 12th-order Morlet wavelet function. Figures 9 and 10 show the derived residuals (left panel) and the wavelet power spectrum (right panel) for electrons and neutrals, respectively. The wavelet power spectrum is shown as a function of spatial scales derived as $v_{\mathrm{R}} / f$, where $v_{\mathrm{R}}$ is the rocket velocity and $f$ is the frequency measured in the rocket frame of reference.

It is apparent that electron density fluctuations become larger above $78 \mathrm{~km}$ and show well-defined structures around 79,82 and $83 \mathrm{~km}$.

Noticeably, the same layers of the enhanced fluctuations are also seen in the neutral density measurements. The advantage of these measurements is that they were done simultaneously on the same deck-facing ram on the upleg and therefore in the same volume, which allows assessment of the joint reaction of neutrals and electrons to the same underlying forcing - likely neutral air turbulence. In the next section we utilize these measured spectra to derive the Schmidt number.

\subsection{Spectral analysis}

We now split the wavelet spectra shown in Figs. 9 and 10 into $100 \mathrm{~m}$ bins and derive the corresponding global wavelet

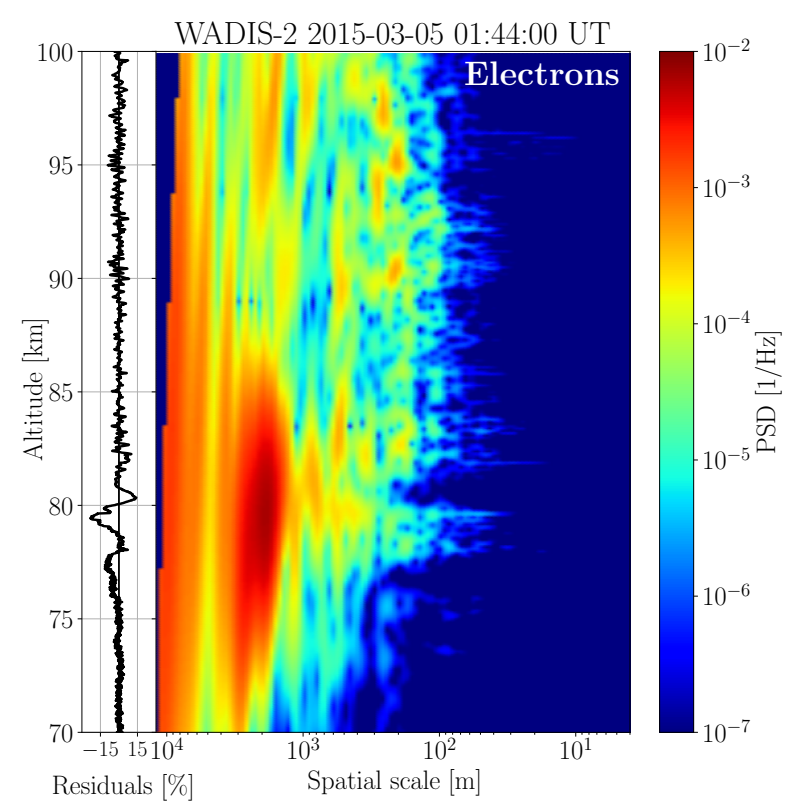

Figure 9. Left panel: measured electron density fluctuations (residuals) of the forward CONE EP from the upleg part of the WADIS-2 flight. Right panel: wavelet power spectrum of the residuals. The wavelet transformation was performed using a 12th-order Morlet wavelet.

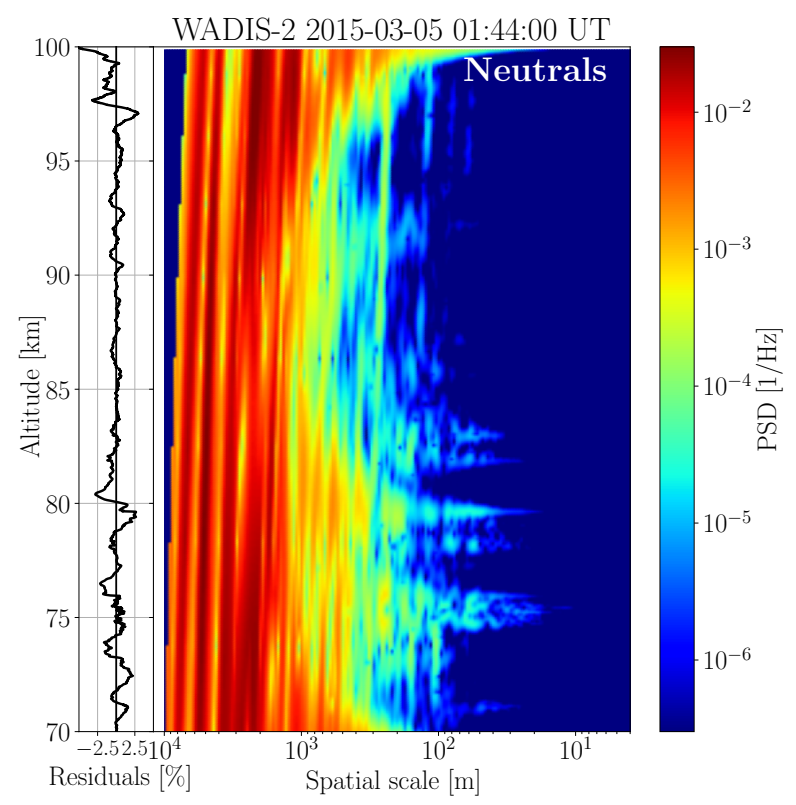

Figure 10. The same as Fig. 9 but for neutral density.

power spectra (Torrence and Compo, 1998). These onedimensional wavelet spectra can further be used to characterize the observed small-scale structures quantitatively. Thus, using the spectral model technique introduced by Lübken (1992), and extended by Strelnikov et al. (2003), it is possible to derive turbulence energy dissipation rate, $\varepsilon$, from the 


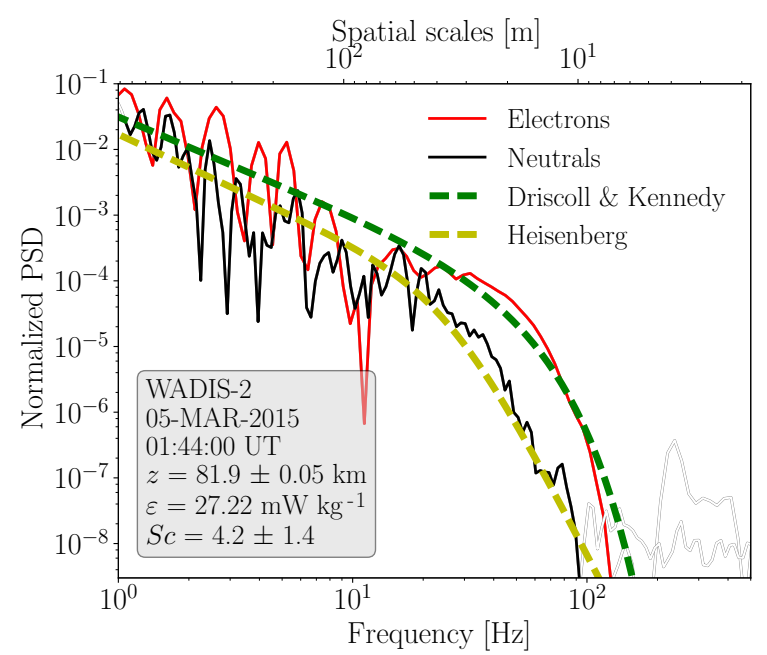

Figure 11. Global wavelet spectrum from 81.85 to $81.95 \mathrm{~km}$ of electron density fluctuations (solid black line) and of neutral density fluctuations (solid red line). The dashed lines shows the best fit of the theoretical models of Driscoll and Kennedy (1985) (green) and of Heisenberg (1948) (yellow). $\varepsilon$ was kept constant for the fit of the Driscoll and Kennedy model to the electron density fluctuations and is obtained from the fit of the Heisenberg model to the neutral density fluctuations. The Driscoll and Kennedy fit yielded a Schmidt number of $S c=4.2 \pm 1.4$.

measured neutral density fluctuations. It is done by fitting a spectral model of a passive scalar tracer in a turbulent field to a measured one-dimensional power spectrum of a corresponding tracer. The derived $\varepsilon$ values can further be used to unambiguously obtain the Schmidt number of other tracers involved in the same turbulent motions (Lübken et al., 1998). This can achieved by fitting a $S c$-dependent spectral model, for example by Driscoll and Kennedy (1985), in which the $\varepsilon$ value has to be known.

Figure 11 demonstrates the described derivation procedure of the Schmidt number. It shows examples of measured spectra (solid lines) at $81.9 \mathrm{~km}$ height alongside with the fitted model spectra (dashed lines). The best fit of the model by Heisenberg (1948) to the spectrum of neutral density fluctuation yields the energy dissipation rate of $27.22 \mathrm{~m} \mathrm{~W} \mathrm{~kg}^{-1}$. From the best fit using the model by Driscoll and Kennedy (1985) $(D \& K)$ to spectrum of electron density fluctuations we derive the Schmidt number of $S c=4.2 \pm 1.4$. The error of the Schmidt number consists of the uncertainty of the least squares fit, the statistical uncertainty of multiple fits with random fit windows and an estimate of the uncertainty propagation of the derived $\varepsilon$ values.

\subsection{Schmidt number profile}

We derive a $S c$-altitude profile by applying the procedure described in the previous section to the measured density fluctuations in the height range $70-100 \mathrm{~km}$. The results for the

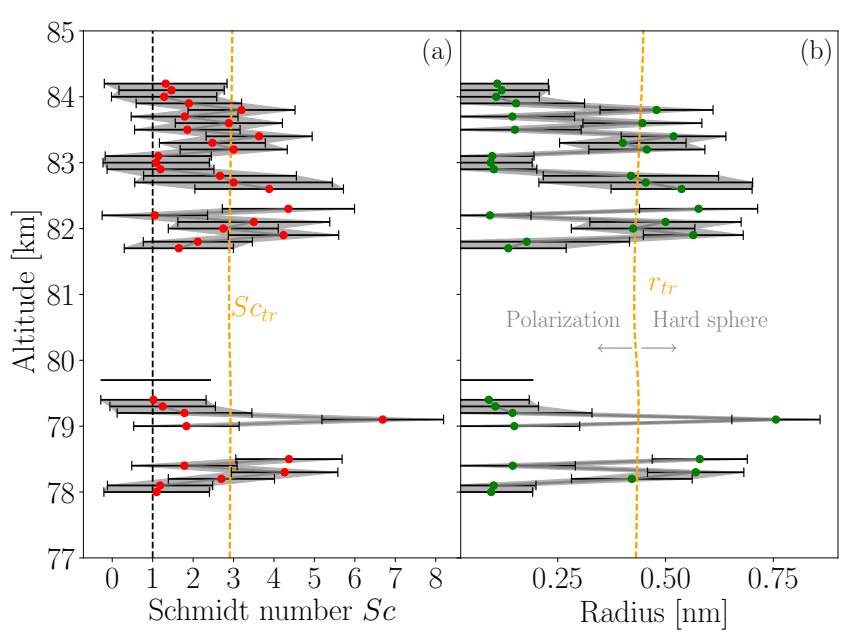

Figure 12. (a) Schmidt number as a function of altitude obtained from fitting the Driscoll and Kennedy theoretical model (red dots). For orientation $S c=1$ is marked by the black dashed line and the transition of polarization and hard sphere interaction by orange dashed line $S c_{\text {tr }}$. The black bars and grey shaded areas indicate the error of the Schmidt numbers (see text for details). (b) Mean charged particle radius $(r \sim \sqrt{S c})$ obtained from Schmidt numbers (green dots). The orange dashed line indicate again the transition between polarization and hard sphere interaction. Error bars are given in black and grey shaded areas (see text for details).

WADIS-2 rocket flight are shown in the left panel of Fig. 12. The smallest Schmidt numbers are not significantly larger than 1 , considering the uncertainty of $S c$. Figure 12 also shows particle radii corresponding to the obtained Schmidt numbers. Details to the derivation of the particle sizes are given hereafter.

Lübken et al. (1998) showed that the Schmidt number of electrons in dusty plasma containing heavy charged aerosols can be related to the radius of those aerosols as $r=\sqrt{S c / 6.5}$ (for $r$ in $\mathrm{nm}$ ). This simple relation, however, can only be applied to dust radii much larger than the mean neutral molecule radius as in the case of mesospheric ice particles in summer. We want to look at small radii and extend this approach. Under the assumption that there are many more charged MSPs than electrons we may write (Lübken et al., 1998)

$S c=\frac{v}{D_{\mathrm{e}}} \approx \frac{v}{D_{\mathrm{d}}}$, for $Z_{\mathrm{d}} \cdot N_{\mathrm{d}} \gg N_{\mathrm{e}}$,

where $D_{\mathrm{e}}$ is the electron and $D_{\mathrm{d}}$ the MSP diffusivity, $Z_{\mathrm{d}}=1$ is the dust charge number, $N_{\mathrm{d}}$ dust number density and $N_{\mathrm{e}}$ is the electron number density. For the smallest particles, induced polarization in the neutral atoms dominates the interaction between particle and neutral molecule. For larger particles a hard sphere interaction model is appropriate. The transition between both models can be derived by equating the collision integrals for both models and solving for the 
particle transition radius yields (Cho et al., 1992)

$r_{\mathrm{tr}}=4.55 \times 10^{-4}\left(\frac{2 \alpha Z_{\mathrm{a}}^{2} e^{2}}{\epsilon_{0} k_{\mathrm{B}} T}\right)^{\frac{1}{4}}-r_{\mathrm{n}}$,

where $\alpha=1.76 \times 10^{-18} \mathrm{~m}^{-3}$ is the neutral atom polarizability, $Z_{\mathrm{a}}$ is the particles charge number, $e$ is the elementary charge, $\epsilon_{0}$ is the vacuum permittivity, $k_{\mathrm{B}}$ is Boltzmann's constant and $T$ is the temperature (assumed to be in thermal equilibrium with the ambient gas). $r_{\mathrm{n}}=1.8 \times 10^{-10} \mathrm{~m}$ is the neutral molecule radius (Cho et al., 1992). Note that Eq. (6) only depends on temperature. A typical value for the winter mesosphere for single charged particles and $T=200 \mathrm{~K}$ is $r_{\mathrm{tr}}=0.45 \mathrm{~nm}$. The diffusivity for particles with $r<r_{\mathrm{tr}}$ is then given by the polarization model as (Cho et al., 1992)

$D_{\mathrm{d}}^{\mathrm{P}}=\frac{9.06 \times 10^{5} k_{\mathrm{B}} T}{N_{\mathrm{n}}\left|Z_{\mathrm{a}}\right| e} \sqrt{\frac{\epsilon_{0}}{\pi \alpha \mu_{\mathrm{dn}}}}$,

where $\mu_{\mathrm{dn}}=\frac{m_{\mathrm{d}} m_{\mathrm{n}}}{m_{\mathrm{d}}+m_{\mathrm{n}}}$ is the reduced mass with the mean molecular mass $m_{\mathrm{n}}$. The MSP mass is given by

$m_{\mathrm{d}}=\frac{4 \pi}{3} \varrho r_{\mathrm{d}}^{3}$,

with the MSP radius $r_{\mathrm{d}}$ and its mass density $\varrho=2 \times$ $10^{3} \mathrm{~kg} \mathrm{~m}^{-3} \cdot N_{\mathrm{n}}$ is the neutral air density. For particles with $r_{\mathrm{dc}}>r_{\mathrm{tr}}$ the diffusivity $D_{\mathrm{d}}$ can be described by a hard sphere model (Cho et al., 1992):

$D_{\mathrm{d}}^{\mathrm{H}}=\frac{3}{8}\left(\frac{k_{\mathrm{B}} T}{2 \pi \mu_{\mathrm{dn}}}\right)^{\frac{1}{2}} \frac{1}{N_{\mathrm{n}}\left(r_{\mathrm{d}}+r_{\mathrm{n}}\right)^{2}}$.

The diffusivities of both models, i.e., polarization and hard sphere, depend on the particle size. In the polarization model the size is implicitly given by the reduced mass $\mu_{\mathrm{dn}}$. By means of Eqs. (8), (7) and (5) one can derive the particle radius as a function of $S c$.

$r_{\mathrm{d}}^{\mathrm{P}}=\sqrt[3]{\frac{3}{4 \pi \varrho} \frac{m_{\mathrm{n}}}{\left(\frac{v}{S c C_{\mathrm{P}}}\right)^{2}-1}}$,

where $C_{\mathrm{P}}=\frac{9.06 \times 10^{5} k \mathrm{~B} T}{N_{\mathrm{n}}\left|Z_{\mathrm{a}}\right| e} \sqrt{\frac{\epsilon_{0}}{\pi \alpha m_{\mathrm{n}}}}$. For particles with radii larger than $r_{\text {tr }}$ the diffusivity described by the hard sphere model is used. Inserting Eq. (9) into Eq. (5) yields

$$
S c=\underbrace{\frac{8}{3} \nu N_{\mathrm{n}} \sqrt{\frac{2 \pi m_{\mathrm{n}}}{k_{\mathrm{B}} T}}}_{C_{\mathrm{H}}} \underbrace{\frac{\left(r_{\mathrm{d}}+r_{\mathrm{n}}\right)^{2}}{\sqrt{1+\frac{m_{\mathrm{n}}}{m_{\mathrm{d}}}}}}_{r_{\mathrm{eff}}^{2}}=C_{\mathrm{H}} \cdot r_{\mathrm{eff}}^{2},
$$

where $v$ is the kinematic viscosity of air and $r_{\text {eff }}$ is an effective radius. Since $C_{\mathrm{H}}$ can be calculated from in situ measurements, we can derive $r_{\text {eff }}$ for each Schmidt number via

$r_{\text {eff }}=\sqrt{\frac{S c}{C_{\mathrm{H}}}}$.

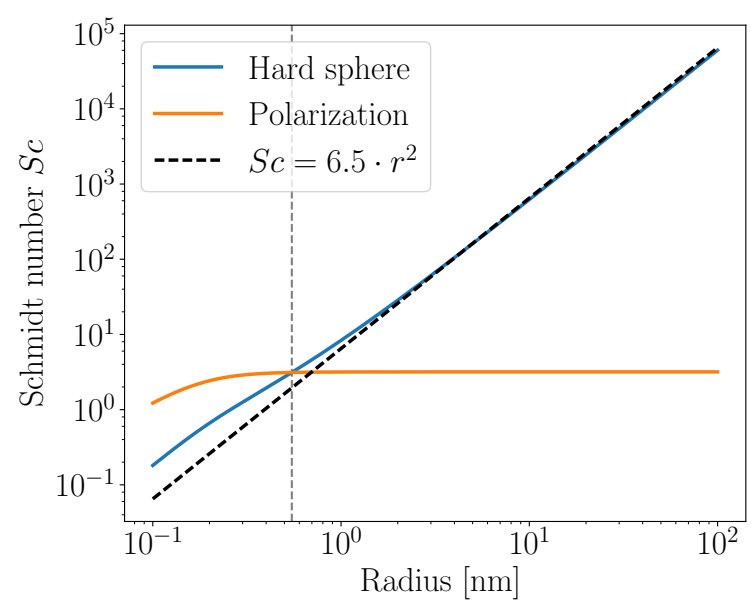

Figure 13. Schmidt number as a function of radius for the two interaction models (hard sphere: blue; polarization: orange) and the expression found by Lübken et al. (1998) (dashed, black) calculated for the conditions given in Lübken et al. (1998). The grey dashed line indicates the radius where the transition between hard sphere and polarization interaction occurs.

In the altitude range between 80 and $85 \mathrm{~km} C_{\mathrm{H}}$ is around $8 \pm 0.1 \mathrm{~nm}^{-2}$, which is slightly larger than the value of $6.5 \mathrm{~nm}^{-2}$ found by Lübken et al. (1998). In the present work we analyze data collected during winter conditions, whereas Lübken et al. (1998) looked at summer condition data. The difference can be found in temperature and density. Figure 13 shows Schmidt numbers calculated for the conditions given in Lübken et al. (1998) as a function of particle radius. The $S c$ for the polarization (blue line) and hard sphere (orange line) interaction model was derived by using $S c=\frac{v}{D}$ and inserting the respective diffusivity. The approximation found by Lübken et al. (1998) is shown by the dashed black line. It is apparent that the simplified relation $S c=C\left(N_{\mathrm{n}}, T\right) \cdot r^{2}$ is valid only for large particles $r \gtrsim 3 \mathrm{~nm}$. For smaller radii the assumption that the charged particle mean radius and mass is large compared to that of the mean neutral molecule is not valid anymore.

However, the parameter of interest in Eq. (12) is the mean charged particle radius $r_{\mathrm{d}}$, which is connected to the effective radius by a linear relation for $r_{\text {eff }} \gtrsim 0.4 \mathrm{~nm}$. This is shown in Fig. 14, where the blue line is the functional behavior of $r_{\text {eff }}^{2}=\frac{\left(r_{\mathrm{d}}+r_{\mathrm{n}}\right)^{2}}{\sqrt{1+m_{\mathrm{n}} / m_{\mathrm{d}}}}$, and in green a linear fit is shown. The corresponding linear equation for $r_{\mathrm{d}}^{\mathrm{H}}$, in nanometers, is

$r_{\mathrm{d}}^{\mathrm{H}}=0.992 \cdot r_{\mathrm{eff}}-0.154$. 


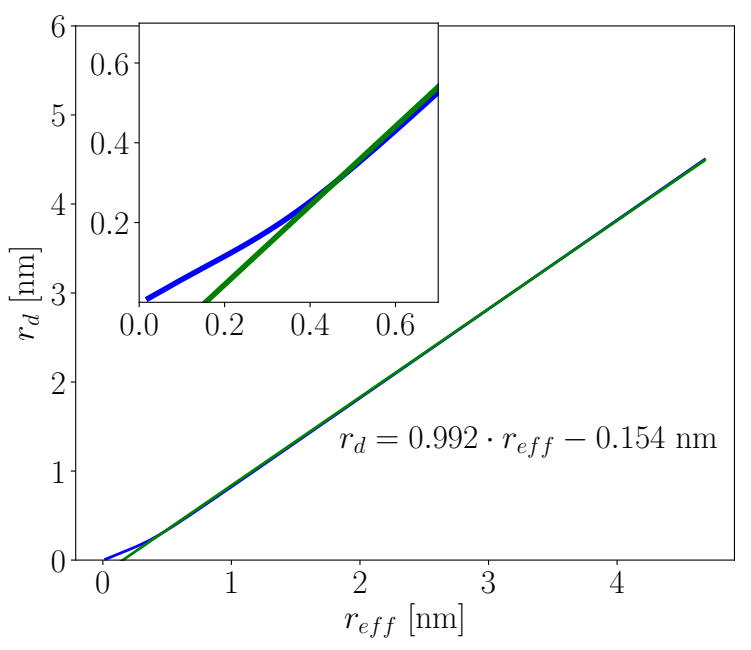

Figure 14. MSP radius to effective radius relation: the blue line shows the MSP radius $r_{\mathrm{d}}$ as a function of the effective radius $r_{\mathrm{eff}}$. A linear fit is shown by the green line.

Using Eq. (12) we can calculate the mean charged particle radius at a given height by

$$
\begin{aligned}
r_{\mathrm{d}}^{\mathrm{H}} & =0.992 \cdot \sqrt{\frac{S c}{C_{\mathrm{H}}}}-0.154 \\
& =0.992 \cdot \sqrt{\frac{3 S c}{8 v N_{\mathrm{n}}} \sqrt{\frac{k_{\mathrm{B}} T}{2 \pi m_{\mathrm{n}}}}}-0.154 .
\end{aligned}
$$

To identify whether the polarization or the hard sphere interaction is dominant, we calculated the Schmidt number which corresponds to the transition radius $r_{\mathrm{tr}}$. The radius can be calculated for each height by Eq. (6) using the in situmeasured temperature. The corresponding Schmidt number can thus be derived by

$S c_{\mathrm{tr}}=\frac{v}{D_{\mathrm{d}}^{\mathrm{H}, \mathrm{P}}\left(r_{\mathrm{tr}}\right)}$,

where $D_{\mathrm{d}}^{\mathrm{H}, \mathrm{P}}$ is either the diffusivity for the hard sphere $D_{\mathrm{d}}^{\mathrm{H}}$ or the polarization $D_{\mathrm{d}}^{\mathrm{P}}$ case at the transition radius $r_{\mathrm{tr}}$. The results for $S c_{\text {tr }}$ and $r_{\text {tr }}$ for WADIS-2 can be found in Fig. 12 . Here the transition Schmidt numbers and radii are shown by the orange dashed lines in the left $\left(S c_{\text {tr }}\right)$ and right $\left(r_{\text {tr }}\right)$ panel, respectively. For Schmidt numbers smaller than $S c_{\text {tr }}$ we calculated the particle radius by means of Eq. (10). For larger Schmidt numbers Eq. (14) was used. The green dots show the radius of the MSPs derived in this way. The maximum Schmidt number revealed by these measurements was 6.6 and the minimum was 1.0 , giving a mean charged particle size from about 0.75 and $0.08 \mathrm{~nm}$, respectively. The derived Schmidt numbers or MSP radii describe an effective mean radius of the aerosols (Lübken et al., 1998) at a given height. We will discuss the obtained results in Sect. 5. It is not an issue that the entire scope of the MSPs has to be described by a distribution function which is as yet unknown. In the next section we assess the width of an assumed distribution function based on the simultaneous common volume in situ measurements described above.

\subsection{Particle size distribution}

In the MLT research, recent works tend to describe particles size distributions by the lognormal distribution (e.g., von Cossart et al., 1999; Berger and von Zahn, 2002; Yamamoto, 2014; Bailey et al., 2015; Rusch et al., 2016). Moreover, model calculations show that neutral MSP size distributions follow lognormal-like distributions (Megner et al., 2006; Plane et al., 2014). With this justification we choose the lognormal size distribution of MSPs to describe the MLT charged dust population observed during the WADIS2 rocket flight. The aerosol density at a given height is then described by the following function:

$f(r)=\frac{N_{\mathrm{d}^{-}}}{\sqrt{2 \pi} \ln \sigma(r-\lambda)} \exp \left(-\frac{1}{2}\left(\frac{\ln \frac{r-\lambda}{\bar{r}}}{\ln \sigma}\right)^{2}\right)$,

where $N_{\mathrm{d}^{-}}$is the density of all negatively charged MSPs, $\sigma$ is the distributions width and $\bar{r}$ is its mean. We added $\lambda$ as a limiting parameter, giving the lower size limit of particles of $0.2 \mathrm{~nm}$ (Hunten et al., 1980).

The entire number of dust particles at a given height can now be calculated by integrating Eq. (16) over the entire population, i.e., for radii from 0 to $\infty$.

$N_{\mathrm{d}^{-}}=\int_{0}^{\infty} f(r) \mathrm{d} r$

Theoretically this integral can be measured as a current of the charged particles onto the PD electrode. In practice, the instrument measures a part of the entire population starting at a critical radius, $r_{\mathrm{c}}$. As shown in Sect. 2.2.2, for a given rocket flight, i.e., defined trajectory and background density and temperature, $r_{\mathrm{c}}$ is height dependent. The measurable fraction of the entire distribution is described by the detection probability function $p(r)$ derived for particles in a mass range from 0-60 000 amu from combined aerodynamical and electrostatic simulations in Sect. 2.2.2. Thus, the measured PD charge density $N_{\mathrm{PD}}$ can be described by a product of two functions: the size distribution function $f(r)$ and the detection probability function $p(r)$. This can be expressed in terms of the measured charge number density at a given height:

$N_{\mathrm{PD}}=\int_{0}^{\infty} p(r) \cdot f(r) \mathrm{d} r$.

In the frame of this work $p(r)$ is a tabulated, discrete function derived for particle radii between 0.58 and $2.28 \mathrm{~nm}$ (see Table A1). 
The difference in measured densities of electrons and positive ions (see Fig. 8) in the height range $75-95 \mathrm{~km}$ can be attributed to charged MSPs, which is in agreement with, for example, Friedrich et al. (2012) and Rapp et al. (2011) and shown in Sect. 3.2. Additionally, during nighttime the majority of the MSPs are singly negatively charged for radii less than $\sim 8 \mathrm{~nm}$ (e.g., Rapp et al., 2011; Robertson et al., 2014; Baumann et al., 2013, 2015; Asmus et al., 2015; Rapp and Lübken, 2001). Thus, we can assume that the entire population of the negatively charged dust particles, $N_{\mathrm{d}^{-}}$, can be derived from the difference of densities of other plasma constituents:

$N_{\mathrm{d}^{-}}=N_{\mathrm{i}^{+}}-N_{\mathrm{e}}$,

where $N_{\mathrm{i}^{+}}$and $N_{\mathrm{e}}$ are measured densities of positive ions and free electrons. The total number of charged particles is thus determined by the measured electron and positive ion density. Changes in those quantities also have an impact on the size distribution; these are considered below.

By combining Eqs. (17) and (19) we can relate the measured plasma densities with the parameters of the size distribution function.

$N_{\mathrm{i}^{+}}-N_{\mathrm{e}}=\int_{0}^{\infty} f(r) \mathrm{d} r$

With Eqs. (18) and (20) we now have a set of two equations using the same size distribution function $f(r)$ given by Eq. (16). The mean MSP radius, $\bar{r}$, was derived from independent $S c$ measurements in Sect. 4.2 and summarized in Fig. 12. The only unknown parameters is the width of the distribution function, $\sigma$. Subsequently, we show results of the set of equations solved numerically.

In Sect. 2.2.2 we showed that the aerodynamics affect the MSP density measurements below $82 \mathrm{~km}$. This implies that the best-quality data to characterize the MSP properties were measured in the range 82 to $90 \mathrm{~km}$. Therefore, we focus on this altitude range to derive the distribution function.

First, we consider the thin layer of $100 \mathrm{~m}$ thickness at $82 \mathrm{~km}$, where the maximum current was measured by the PDs. The mean measured charge density shown in Fig. 8 reveals a value of $N_{\mathrm{PD}}=224 \mathrm{~cm}^{-3}$ at $82 \mathrm{~km}$ height. The mean MSP radius derived from independent $S c$ measurements in Sect. 4.2 at this height results in a value of $\bar{r}=0.56 \mathrm{~nm}$ (see also Fig. 12). The charge difference derived from the measured densities of electrons and positive ions shown in Fig. 8 reveals a value of $10000 \mathrm{~cm}^{-3}$, which is almost 2 orders of magnitude higher than the MSP charge density measured by the PD. Substituting these values in Eqs. (16), (18) and (20) we derive $\sigma=1.66$. In practice, we change $\sigma$ until the integral of $p(r) \cdot f(r)$ over all $r$ values reaches the measured peak value of $224 \mathrm{e} \mathrm{cm}^{-3}$ and the integral of $f(r)$ over all $r$ values becomes equal to the charge difference between electrons and positive ions of $10000 \mathrm{ecm}^{-3}$. This difference, however,

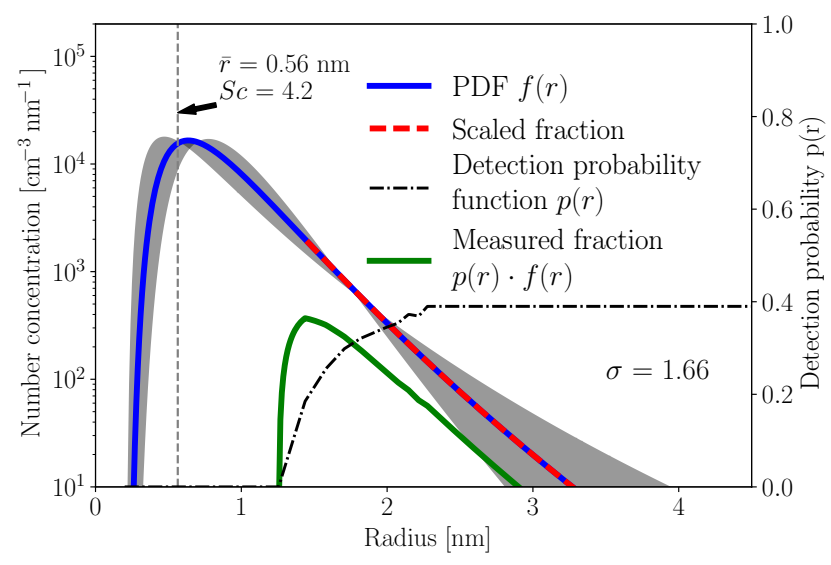

Figure 15. Particle size density as a function of radius (solid lines, left-hand $y$ axis). The blue line shows the estimated lognormal size distribution and the green line the size distribution most likely seen as integral by the PD at $82 \mathrm{~km}$. The red dashed line indicates the fraction of the distribution contributing to the PD current. The dashed dotted line shows the detection probability of the PD as obtained from aerodynamic simulations (right-hand $y$ axis). The grey shaded areas indicate the error of the distribution due to the uncertainty of $S c$.

is dependent on the uncertainty of the measurements of electron and ion density. To assess the impact of those uncertainties on the distribution width we estimated the uncertainty of charge difference $N_{\mathrm{e}}-N_{\mathrm{i}^{+}}$to be a factor of 2. Reducing $N_{\mathrm{e}}-N_{\mathrm{i}^{+}}$by this factor would cause an increase in the distribution width by 0.3 , i.e., to $\sigma=1.96$, whereas increased difference by a factor of 2 causes the width to be decreased by 0.14 , i.e., to $\sigma=1.52$. These changes are on the same order as the uncertainty introduced by the Schmidt number.

Figure 15 shows the resulting size distribution of MSPs at $82 \mathrm{~km}$ height. The derived lognormal size distribution of aerosols at $82 \mathrm{~km}$ is given by the blue line. The black dashed dotted line is the particle detectors detection probability function $p(r)$. The measured fraction of the MSPs is indicated by the green line. As shown above, it can be expressed as a product of the distribution function and the detection efficiency function, $f(r) \cdot p(r)$. That is, using these two curves (the green and the black dash-dotted) we reconstructed the part of the distribution function shown by the red dashed line. The uncertainty due to the error in the Schmidt number is indicated by the grey shaded areas. The most relative variance is found for larger radii.

Our $S c$ analysis summarized in Fig. 12 shows that the observed MSP layer between 75 and $90 \mathrm{~km}$ may consist of several sublayers of different sizes. Thus, considering the height range 81 to $85 \mathrm{~km}$, we derive the mean by using only Schmidt numbers larger than $S c_{\text {tr }}$. The resulting $S c$ is 3.3 and the corresponding radius is $0.48 \mathrm{~nm}$. The difference to the thin dust layer is within the uncertainty of the analysis. 


\section{Discussion}

Aerosols play an important role in the physics of the MLT region. They can have major impacts, for example, on the charge balance of the lower ionosphere. In the presence of those aerosols, the number density of free electrons during nighttime is likely reduced relative to the positive ion density since electrons attach to those aerosols (e.g., Brattli et al., 2009; Rapp et al., 2011; Baumann et al., 2013, 2015). As a consequence there can be large differences between the electron and positive ion density depending on the number of electrons attached to aerosols. A large difference between electrons and positive ions was also seen by our measurements (Fig. 8). Below $104 \mathrm{~km}$ the measured density profiles show an increasing discrepancy indicating that it is necessary to account for charged aerosols to satisfy the quasi-neutrality condition for the ionospheric plasma in the mesopause region. The same feature has also been observed before by, for example, Friedrich et al. (2011) and Friedrich et al. (2012). At $85 \mathrm{~km}$ there is approximately 1 order of magnitude more positive ions than electrons. The charge densities measured with the PDs indicate that this discrepancy can be attributed to the presence of heavy, predominately negatively charged MSPs at least between 92 and $75 \mathrm{~km}$. Note that besides negative dust also negative ions, which were not measured in the frame of the WADIS mission, are an important player in the charge balance in the lower D region (e.g., Baumann et al., 2013, 2015; Plane et al., 2014; Asmus et al., 2015). Nevertheless, negative ion density (predominantly $\mathrm{NO}_{3}^{-}$and $\mathrm{O}_{2}^{-}$at night around $80 \mathrm{~km}$ ) are thought to rapidly decrease above $80 \mathrm{~km}$ during nighttime due to destruction by atomic oxygen (Thomas and Bowman, 1985; Friedrich et al., 2012; Plane et al., 2014; Baumann et al., 2015). In situ measurements of O density (not shown here) on WADIS-2 show a rapid increase above $\sim 77 \mathrm{~km}$, which supports the assumption that negative ions play only a minor role in the charge balance at those heights. Thus, the assumption that the charge balance is dominated by free electrons, positive ions and charged MSPs above $80 \mathrm{~km}$ is justified.

The charged particle density measured by the PD is approximately 2 orders of magnitude less around $85 \mathrm{~km}$ than the difference between positive ions and electrons. This can be explained by aerodynamic filtering of measured particle densities by rocket-borne detectors. In situ measurements of charged aerosols are influenced by the aerodynamic conditions around the rocket body and electrostatic properties of the detecting instrument.

However, the combined aerodynamic and electrostatic simulations in Sect. 2.2.2 showed that the decreasing current seen by the Faraday cups above $82 \mathrm{~km}$ is not due to aerodynamic filtering. It can rather be addressed to the decrease in MSP density with radii $\gtrsim 1 \mathrm{~nm}$.

According to our current understanding summarized by, for example, Rapp and Lübken (2004), neutral air turbulence in the mesosphere creates small-scale structures in all plasma species, including charged aerosols, electrons and ions. The heavier plasma components are collisionally dominated and behave as a passive tracer. The electrons are electrostatically coupled to the plasma components of the opposite charge and thereby show the same turbulent structures. The presented measurements of electrons and neutral gas density fluctuations show that there are structures at the same altitude range in both neutrals and electrons. We found that the electrons were structured down to smaller scales than the neutrals (see Fig. 11), which is an indication of the presence of heavy charged particles. In summer, when large ice particles are present in the mesopause region, this leads to the creation of the PMSEs (e.g., Cho et al., 1992; Rapp and Lübken, 2004). This effect can be described by an enhanced Schmidt number $S c=\frac{v}{D}$, i.e., the ratio of kinematic viscosity of air, $v$, to diffusivity $D$, of electrons. The $S c$ of electrons is becoming large due to their ultimate electrostatic coupling to heavy charged aerosols whose diffusivity is significantly reduced because of their mass. Typical values for $S c$ found in PMSEs are several hundred on average and can often be several thousands (Lübken et al., 1994; Li et al., 2010; Rapp et al., 2011; Strelnikov et al., 2009; Strelnikov and Rapp, 2011). The same mechanism but involving MSPs was proposed to explain the PMWEs in the case when neutral turbulence is not sufficiently large (e.g., Kavanagh et al., 2006; Lübken et al., 2007; Kero et al., 2008; La Hoz and Havnes, 2008; Havnes and Kassa, 2009; Havnes et al., 2011; Strelnikova and Rapp, 2013; Stebel et al., 2004; Belova et al., 2008). The latter has not yet been confirmed by direct measurement. The MLT ice particles in summer reveal sizes of tens of nanometers to $100 \mathrm{~nm}$ diameter (e.g., Berger and von Zahn, 2002; Bailey et al., 2015) and consist of water ice. In winter the sizes of MSPs are significantly smaller, i.e., up to some nanometers (e.g., Strelnikova et al., 2007; Kero et al., 2008; La Hoz and Havnes, 2008; Belova et al., 2008; Havnes and Kassa, 2009; Fentzke et al., 2009; Robertson et al., 2014; Rapp et al., 2010, 2012; Strelnikov et al., 2012). Hence, in winter $S c$ will be much smaller as it is connected to the radius by $S c \sim r^{2}$ (Lübken et al., 1998, and Sect. 4.2). From our measurements we obtain Schmidt numbers between 3 and 7, supporting the hypothesis that the effect of reducing electron diffusivity by charged MSPs above $80 \mathrm{~km}$ in winter during nighttime is rather small. Using uncommon volume measurements of neutrals, positive ions and MSPs, Schmidt numbers for winter conditions were also derived by Strelnikov et al. (2012), showing comparably small $S c$. They also compared spectral features at large scales $(>100 \mathrm{~m})$ and stated that turbulent structures are different between upleg and downleg $(\sim 50 \mathrm{~km})$ and common volume measurements of charged and neutral species are needed for a robust derivation of $S c$. As reported in this paper, with the WADIS-2 payload we were able to achieve this requirement for the first time.

To convert the measured Schmidt number to particle radii, we followed the work of Cho et al. (1992), where two models were considered for charged particle-neutral interaction via 
collisions. These models are the hard sphere and the polarization model whereas the hard sphere model applicable to large aerosols and the polarization model, relevant for small particles. Since we deal with relatively small Schmidt numbers, we considered the corresponding particle size to be in the transition region between those two models. Hence, we looked at the relation between $S c$ and $r$ at small radii considering both models. The results show that calculated particle sizes in the polarization interaction case are in the size range of molecules. In this case there is no indication whether the diffusivity of electrons is dominated by MSPs or molecular ions. We therefore conclude that for Schmidt numbers smaller than the transition Schmidt number $S c_{\text {tr }}$ the derivation of MSP radii from electron density fluctuations is not appropriate. The lower limit of the connection between Schmidt number and aerosol size is the transition between hard sphere and polarization interaction given by the transition radius $r_{\text {tr }}$ and the corresponding $S c_{\text {tr }}$. In the case for the polar winter mesopause region we derived this limit as $r_{\mathrm{tr}} \approx 0.45 \mathrm{~nm}$ and $S c_{\mathrm{tr}} \approx 3$, respectively.

The derivation of the Schmidt number involves uncertainties which come from different sources, which are, for example, the error of the $\varepsilon$ derivation and the error of the least squares fit to the measured spectra of the electron density fluctuations. Other uncertainties such as temperature and density measurement errors are negligible. As can be seen from Fig. 12, Schmidt numbers larger than 1 do exist, even if the errors are considered. Hence, the $S c$ measurements confirm the presence of charged particles and their influence on the electron diffusivity.

The very small MSPs are formed from the material deposited by incoming meteorites (e.g., Rosinski and Snow, 1961; Hunten et al., 1980). They are thought to grow via homogeneous nucleation and coagulation processes which yield an altitude-dependent size distribution (e.g., Megner et al., 2006). Model results show that the particle size increases with decreasing altitude (Hunten et al., 1980; Megner et al., 2006; Plane et al., 2014). The same was also shown by in situ measurements for charged particles (Robertson et al., 2014). Other properties, such as charge state and composition of charged MSPs, were measured in situ (e.g., Rapp et al., 2010,2012 ) and by ground-based radar measurement techniques (Strelnikova et al., 2007; Fentzke et al., 2009). The latter is only possible when MSPs produce secondary effects by influencing properties of ionospheric plasma which leads to radar echoes (PMWEs). There are also active radar experiments that heat free electrons at MLT heights by HF waves emitted from the ground and, in parallel, examine the behavior of PMWEs in VHF band (Kero et al., 2008; Havnes and Kassa, 2009; La Hoz and Havnes, 2008; Belova et al., 2008; Havnes et al., 2011). The so-called heating experiments gave a strong indication that dust is involved in the PMWE formation and that there are large charged particles on the order of $\sim 3 \mathrm{~nm}$ at lower altitudes (Havnes et al., 2011) which also substantiate the increase in the number of large particles with decreasing altitude. This is also in agreement with the results shown in the left panel of Fig. 8.

Our size estimate based on the obtained $S c$ suggests that a large number of very small MSPs, i.e., with $r<1 \mathrm{~nm}$ was present around $80 \mathrm{~km}$. The existence of very small MSPs with radii less than $1 \mathrm{~nm}$ in the winter mesosphere was shown by remote sensing techniques as well as in situ experiments (e.g., Strelnikova et al., 2007; Fentzke et al., 2009; Robertson et al., 2014). The size of the particles is a crucial parameter in the electron diffusivity and hence in the radar backscatter theory. The mean particle radii found in this study are in agreement with earlier findings. However, in situ measurements to quantify the size distribution of the MSPs are very rare and rather coarse (Robertson et al., 2014). By means of the mean radius obtained from the Schmidt numbers (see Sect. 4), the difference between electron and positive ion density, and the integrated density of charged particles down to the detection limit of the PD, we estimated the size distribution of the charged MSPs in Sect. 4.3. The resulting distribution shows that $99.9 \%$ of the charged particles are smaller than $\sim 4 \mathrm{~nm} ; 90 \%$ are smaller than $\sim 1.7 \mathrm{~nm}$. In comparison with model results of neutral MSPs, where approximately $96 \%$ of the particles are smaller than $1 \mathrm{~nm}$ (Megner et al., 2006), we found that there are relatively more charged particles of larger sizes than in the modeled neutral size distribution. Hence, this confirms that smallest particles are less likely to become charged. The influence of the estimated uncertainty in the total charge difference between electrons and positive ions was found to be on the order of the uncertainty introduced by the Schmidt number derivation.

The charging rate of aerosols increases proportionally to their cross section (Natanson, 1960). As already mentioned, model calculations showed that the number density of all MSPs decreases with size (e.g., Megner et al., 2006). The size distribution of charged MSPs $f(r)$ is a product of the charging probability and the neutral dust size distribution. Therefore our distribution function accounts for two processes. The first is the increase in MSP size with decreasing height due to growth, sedimentation and coagulation. This behavior is also apparent in our results seen in Figs. 8 and 12. The second process accounts for the smallest particles being less likely to become charged (Plane et al., 2014) and hence the density of charged MSPs with small radii decreases. Considering the location and width parameter of the size distribution function, which is given by its mean $\bar{r}$ and width $\sigma$, we find that the particle size range is in agreement with other in situ and remote findings yielding particle sizes in the range of 0.5 to $1.5 \mathrm{~nm}$ (Robertson et al., 2014; Strelnikova et al., 2007; Fentzke et al., 2009, 2012). Compared to size distributions obtained from the model of MSPs at $90 \mathrm{~km}$, regardless of their charge, the number of particles with $0.5 \mathrm{~nm}$ is on the same order of magnitude as found in the model (Megner et al., 2006, Fig. 2). The derived charged particle distribution shows more particles at larger radii than found for MSPs by models Megner et al. (2006). However, as Megner et al. 
(2006), for example, showed, their model output is highly dependent on less well known parameters such as coagulation rate, eddy diffusion and meteoric input and the difference to our results are in the model uncertainty. We assume a lognormal distribution of charged MSPs. However, other shapes of the distribution could be possible. For instance, more than one maximum is conceivable. This is heavily dependent on the so-called "sticking coefficient" of electrons to the smallest MSP since there are a lot more small than large particles above $80 \mathrm{~km}$ (e.g., Megner et al., 2006; Robertson et al., 2014). The sticking coefficients are not well known and depend on the dust material (Plane et al., 2014). Thus, more size-resolving measurements of neutral and charged dust in the mesosphere are highly needed, but further study of charging processes of smallest aerosols is also required.

Our findings show that the dust is structured in layers of increased density of large particles. These structures can be found in the left panel of Fig. 8 around 78 and $79 \mathrm{~km}$ as locally increased density. Additionally, those structures can be found in both profiles of the PD measurements, which indicates that these are not artifacts but rather a real geophysical feature. At the same heights, independent measurements show that there are increased Schmidt numbers, i.e., mean particle radii (see Fig. 12). Since both those techniques are more sensitive to larger MSPs, this clearly indicates layers of large MSPs. That is, our measurements show that, on top of the continuous MSP background spanning over $\sim 20 \mathrm{~km}$ (i.e., $75-92 \mathrm{~km}$ ), there are layers of larger MSPs. These layers are of $\sim 0.3 \mathrm{~km}$ in extent and they are separated by $\sim 1 \mathrm{~km}$. The study of the exact mechanism behind this layering lies beyond the scope of the present work.

\section{Conclusions}

In this work we presented results of in situ measurements of MLT dusty-plasma densities, including electrons, positive ions and charged aerosols conducted during the WADIS-2 sounding rocket campaign. Neutral air density fluctuations were also measured, allowing for robust derivation of turbulence energy dissipation rates. A unique feature of all these measurements is that for the first time they were done in a common volume and with high spatial resolution.

The MSP densities were measured with a classical Faraday cup. These measurements are known to be affected by the aerodynamics of the sounding rocket flight as well as the electrostatic potentials of the instrument's grids. We quantified this influence from combined electrostatic and aerodynamic simulations and derived a height-dependent critical radius. Based on these simulations we conclude that the measured densities of charged MSPs reflect real size-altitude dependence above $82 \mathrm{~km}$. Above those heights the electrostatic barrier of the grid potentials limits the size of the detectable particles. The measured MSP densities below $82 \mathrm{~km}$ are a product of the real density and the height-dependent aerody- namic filtering and therefore have been analyzed considering the aerodynamic effects.

We also derived an altitude profile of Schmidt numbers from electron density fluctuations with $100 \mathrm{~m}$ resolution. These $S c$ numbers were converted to MSP radii by applying two different models, i.e., polarization and hard sphere model for very small and larger MSPs, respectively. These are the first reliable in situ measurements of MSP radii based on $S c$ for winter conditions. Our measurements reveal a very large number of small $(r<2 \mathrm{~nm})$ MSPs. These findings are in agreement with previous studies. Therefore, we derived a transition value for $S c$ and $r$ and conclude that below this value the conversion of $S c$ to $r$ is not reliable. For the WADIS-2 flight conditions, i.e., polar winter night, these values are $S c_{\text {tr }}=3$ and $r_{\text {tr }}=0.45 \mathrm{~nm}$. The derived mean radius of the charged MSPs was $r=0.56 \mathrm{~nm}$ in the altitude range 81.9 to $82.0 \mathrm{~km}$ and $r=0.48 \mathrm{~nm}$ in the range $81-85 \mathrm{~km}$. The difference lies within the uncertainty limits of this technique.

Due to the unique constellation of instruments, all the measurements were done in the same volume, and we were able to reliably derive an MSP size distribution function assuming lognormal shape. The derived width in log scale of the distribution function is 1.66 for the height range $81.9-82.0 \mathrm{~km}$ and 1.76 for the range $81-85 \mathrm{~km}$. However, the presented technique has inevitable uncertainties and needs to be validated by a more direct in situ measurement of charged particle size distribution.

We also found that the thick continuous layer of charged MSPs observed by the PD between $\sim 75$ and $92 \mathrm{~km}$ showed inhomogeneities in terms of enhanced charged MSP density. Those inhomogeneities coincide with enhanced electron Schmidt numbers. Thus, the large particles with sizes $>1 \mathrm{~nm}$ were stratified in layers of $\sim 1 \mathrm{~km}$ thickness and lying some kilometers apart from each other. This phenomenon might be connected to wave activity or neutral turbulence. However the exact mechanism of this layering remains unclear and will be the subject of future studies.

Data availability. Data can be obtained by contacting the author (asmus@iap-kborn.de). 


\section{Appendix A: Detection efficiency at $82 \mathrm{~km}$}

In Table A1 we summarized the results of the 2-D and 3D combined aerodynamic and electrostatic simulations described in Sect. 2.2.2.

Table A1. Particle detector detection efficiency $p(r)$ at $82 \mathrm{~km}$.

\begin{tabular}{lrr}
\hline Mass (amu) & Radius (nm) & Detection efficiency $(\%)$ \\
\hline 1000 & 0.58 & 0 \\
2500 & 0.79 & 0 \\
5000 & 1.00 & 0 \\
10000 & 1.26 & 0 \\
15000 & 1.44 & 18.5 \\
20000 & 1.58 & 25.6 \\
25000 & 1.70 & 29.8 \\
30000 & 1.81 & 32.0 \\
35000 & 1.91 & 33.3 \\
40000 & 1.99 & 34.5 \\
45000 & 2.07 & 35.4 \\
50000 & 2.15 & 37.3 \\
55000 & 2.22 & 36.9 \\
60000 & 2.28 & 39.2 \\
\hline
\end{tabular}


Competing interests. The authors declare that they have no conflict of interest.

Acknowledgements. This study was supported by the German Space Agency (DLR) under grant 50 OE 1001 (project WADIS). The authors would like to thank Torsten Köpnick and HansJürgen Heckl for their excellent work in manufacturing and technical development of the instruments.

The topical editor, Petr Pisoft, thanks Ove Havnes and one anonymous referee for help in evaluating this paper.

\section{References}

Asmus, H., Strelnikov, B., and Rapp, M.: In situ measurements of charged mesospheric ice particles during the PHOCUS 2011 campaign and comparison of the results with a microphysical MODEL, in: European Space Agency, (Special Publication) ESA SP, vol. 721 SP, 489-493, 2013.

Asmus, H., Robertson, S., Dickson, S., Friedrich, M., and Megner, L.: Charge balance for the mesosphere with meteoric dust particles, J. Atmos. Sol.-Terr. Phy., 127, 137-149, https://doi.org/10.1016/j.jastp.2014.07.010, 2015.

Bailey, S. M., Thomas, G. E., Hervig, M. E., Lumpe, J. D., Randall, C. E., Carstens, J. N., Thurairajah, B., Rusch, D. W., Russell, J. M., and Gordley, L. L.: Comparing nadir and limb observations of polar mesospheric clouds: The effect of the assumed particle size distribution, J. Atmos. Sol.-Terr. Phy., 127, 51-65, https://doi.org/10.1016/j.jastp.2015.02.007, 2015.

Baumann, C., Rapp, M., Kero, A., and Enell, C.-F.: Meteor smoke influences on the D-region charge balance - review of recent in situ measurements and one-dimensional model results, Ann. Geophys., 31, 2049-2062, https://doi.org/10.5194/angeo31-2049-2013, 2013.

Baumann, C., Rapp, M., Anttila, M., Kero, A., and Verronen, P. T.: Effects of meteoric smoke particles on the D region ion chemistry, J. Geophys. Res.-Space, 120, 10823-10839, https://doi.org/10.1002/2015JA021927, 2015.

Bekkeng, T. A., Barjatya, A., Hoppe, U.-P., Pedersen, A., Moen, J. I., Friedrich, M., and Rapp, M.: Payload charging events in the mesosphere and their impact on Langmuir type electric probes, Ann. Geophys., 31, 187-196, https://doi.org/10.5194/angeo-31187-2013, 2013.

Belova, E., Smirnova, M., Rietveld, M. T., Isham, B., Kirkwood, S., and Sergienko, T.: First observation of the overshoot effect for polar mesosphere winter echoes during radiowave electron temperature modulation, Geophys. Res. Lett., 35, L03110, https://doi.org/10.1029/2007GL032457, 2008.

Bennett, F., Hall, J., and Dickinson, P.: D-region electron densities and collision frequencies from Faraday rotation and differential absorption measurements, J. Atmos. Terr. Phys., 34, 1321-1335, https://doi.org/10.1016/0021-9169(72)90188-2, 1972.

Berger, U. and von Zahn, U.: Icy particles in the summer mesopause region: Three-dimensional modeling of their environment and two-dimensional modeling of their transport, J. Geophys. Res.Space, 107, 1366, https://doi.org/10.1029/2001JA000316, 2002.

Bird, G. A.: Molecular gas dynamics and the direct simulation of gas flows, vol. 42 of Oxford engineering science series, Claren- don Press and Oxford University Press, Oxford and New York, 1994.

Blix, T. A., Thrane, E. V., and Andreassen, Ø.: In situ measurements of the fine-scale structure and turbulence in the mesosphere and lower thermosphere by means of electrostatic positive ion probes, J. Geophys. Res., 95, 5533, https://doi.org/10.1029/JD095iD05p05533, 1990.

Brattli, A., Lie-Svendsen, Ø., Svenes, K., Hoppe, U.-P., Strelnikova, I., Rapp, M., Latteck, R., and Friedrich, M.: The ECOMA 2007 campaign: rocket observations and numerical modelling of aerosol particle charging and plasma depletion in a PMSE/NLC layer, Ann. Geophys., 27, 781-796, https://doi.org/10.5194/angeo-27-781-2009, 2009.

Cho, J. Y. N., Hall, T. M., and Kelley, M. C.: On the Role of Charged Aerosols in Polar Mesosphere Summer Echoes, J. Geophys. Res., 97, 875-886, 1992.

Dalmann, B.-K., Grün, E., Kissel, J., and Dietzel, H.: The ion-composition of the plasma produced by impacts of fast dust particles, Planet. Space Sci., 25, 135-147, https://doi.org/10.1016/0032-0633(77)90017-4, 1977.

Dieminger, W., Hartmann, G. K., and Leitinger, R.: The Upper Atmosphere: Data Analysis and Interpretation, Springer Berlin Heidelberg, 1996.

Driscoll, R. J. and Kennedy, L. A.: Model for the Spectrum of Passive Scalars in an Isotropic Turbulence Field, Phys. Fluids, 28, 72-80, https://doi.org/10.1063/1.865128, 1985.

Fentzke, J., Janches, D., Strelnikova, I., and Rapp, M.: Meteoric smoke particle properties derived using dual-beam Arecibo UHF observations of D-region spectra during different seasons, J. Atmos. Sol.-Terr. Phy., 71, 1982-1991, https://doi.org/10.1016/j.jastp.2009.09.002, 2009.

Fentzke, J. T., Hsu, V., Brum, C. G. M., Strelnikova, I., Rapp, M., and Nicolls, M.: D region meteoric smoke and neutral temperature retrieval using the Poker Flat incoherent scatter radar, Geophys. Res. Lett., 39, L21102, https://doi.org/10.1029/2012GL053841, 2012.

Folkestad, K.: Ionospheric Studies by in situ measurements in sounding rockets, Phd, University of Oslo, 1970.

Friedrich, M., Rapp, M., Plane, J. M. C., and Torkar, K. M.: Bite-outs and other depletions of mesospheric electrons., J. Atmos. Sol.-Terr. Phy., 73, 2201-2211, https://doi.org/10.1016/j.jastp.2010.10.018, 2011.

Friedrich, M., Rapp, M., Blix, T., Hoppe, U.-P., Torkar, K., Robertson, S., Dickson, S., and Lynch, K.: Electron loss and meteoric dust in the mesosphere, Ann. Geophys., 30, 1495-1501, https://doi.org/10.5194/angeo-30-1495-2012, 2012.

Friedrich, M., Torkar, K. M., Hoppe, U.-P., Bekkeng, T.-A., Barjatya, A., and Rapp, M.: Multi-instrument comparisons of Dregion plasma measurements, Ann. Geophys., 31, 135-144, https://doi.org/10.5194/angeo-31-135-2013, 2013.

Gelinas, L. J., Lynch, K. A., Kelley, M. C., Collins, S., Baker, S., Zhou, Q., and Friedman, J. S.: First observation of meteoritic charged dust in the tropical mesosphere, Geophys. Res. Lett., 25, 4047-4050, https://doi.org/10.1029/1998GL900089, 1998.

Giebeler, J., Lübken, F.-J., and Nägele, M.: CONE - a new sensor for in-situ observations of neutral and plasma density fluctuations, ESA-SP-355, 311-318, 1993. 
Gumbel, J.: Aerodynamic influences on atmospheric in situ measurements from sounding rockets, J. Geophys. Res.-Space, 106, 10553-10563, https://doi.org/10.1029/2000JA900166, 2001.

Havnes, O. and Kassa, M.: On the sizes and observable effects of dust particles in polar mesospheric winter echoes, J. Geophys. Res., 114, D09209, https://doi.org/10.1029/2008JD011276, 2009.

Havnes, O. and Næsheim, L. I.: On the secondary charging effects and structure of mesospheric dust particles impacting on rocket probes, Ann. Geophys., 25, 623-637, https://doi.org/10.5194/angeo-25-623-2007, 2007.

Havnes, O., Trøim, J., Blix, T., Mortensen, W., Næsheim, L. I., Thrane, E., and Tønnesen, T.: First detection of charged dust particles in the Earth's mesosphere, J. Geophys. Res., 101, 1083910847, 1996.

Havnes, O., La Hoz, C., Rietveld, M. T., Kassa, M., Baroni, G., and Biebricher, A.: Dust charging and density conditions deduced from observations of PMWE modulated by artificial electron heating, J. Geophys. Res.-Atmos., 116, D24203, https://doi.org/10.1029/2011JD016411, 2011.

Hedin, J., Gumbel, J., and Rapp, M.: On the efficiency of rocketborne particle detection in the mesosphere, Atmos. Chem. Phys., 7, 3701-3711, https://doi.org/10.5194/acp-7-3701-2007, 2007.

Heisenberg, W.: Zur statistischen Theorie der Turbulenz, Zeitschrift für Physik, 124, 628-657, https://doi.org/10.1007/BF01668899, 1948.

Hervig, M. E., Gordley, L. L., Deaver, L. E., Siskind, D. E., Stevens, M. H., Russell, J. M., Bailey, S. M., Megner, L., and Bardeen, C. G.: First Satellite Observations of Meteoric Smoke in the Middle Atmosphere, Geophys. Res. Lett., 36, L18805, https://doi.org/10.1029/2009GL039737, 2009.

Horányi, M., Gumbel, J., Witt, G., and Robertson, S.: Simulation of rocket-borne particle measurements in the mesosphere, Geophys. Res. Lett., 26, 1537-1540, https://doi.org/10.1029/1999GL900298, 1999.

Hunten, D. M., Turco, R. P., and Toon, O. B.: Smoke and Dust Particles of Meteoric Origin in the Mesosphere and Stratosphere, J. Atmos. Sci., 37, 1342-1357, 1980.

Jacobsen, T. A. and Friedrich, M.: Electron density measurements in the lower D-region, J. Atmos. Terr. Phys., 41, 1195-1200, https://doi.org/10.1016/0021-9169(79)90022-9, 1979.

Kassa, M., Rapp, M., Hartquist, T. W., and Havnes, O.: Secondary charging effects due to icy dust particle impacts on rocket payloads, Ann. Geophys., 30, 433-439, https://doi.org/10.5194/angeo-30-433-2012, 2012.

Kavanagh, A., Honary, F., Rietveld, M., and Senior, A.: First observations of the artificial modulation of polar mesospheric winter echoes, Geophys. Res. Lett., 33, 19801, https://doi.org/10.1029/2006GL027565, 2006.

Kero, A., Enell, C.-F., Kavanagh, A. J., Vierinen, J., Virtanen, I., and Turunen, E.: Could negative ion production explain the polar mesosphere winter echo (PMWE) modulation in active HF heating experiments?, Geophys. Res. Lett., 35, L23102, https://doi.org/10.1029/2008GL035798, 2008.

Kirkwood, S., Chilson, P., Belova, E., Dalin, P., Häggström, I., Rietveld, M., and Singer, W.: Infrasound - the cause of strong Polar Mesosphere Winter Echoes?, Ann. Geophys., 24, 475-491, https://doi.org/10.5194/angeo-24-475-2006, 2006.
La Hoz, C. and Havnes, O.: Artificial modification of polar mesospheric winter echoes with an RF heater: Do charged dust particles play an active role?, J. Geophys. Res., 113, D19205, https://doi.org/10.1029/2008JD010460, 2008.

Latteck, R., Singer, W., Rapp, M., Vandepeer, B., Renkwitz, T., Zecha, M., and Stober, G.: MAARSY: The new MST radar on Andøya-System description and first results, Radio Science, 47, RS1006, https://doi.org/10.1029/2011RS004775, 2012.

Li, H., Wu, J., Wu, J., Xu, Z.-W., and Xu, B.: Study on the layered dusty plasma structures in the summer polar mesopause, Ann. Geophys., 28, 1679-1686, https://doi.org/10.5194/angeo28-1679-2010, 2010.

Lübken, F.-J.: On the extraction of turbulent parameters from atmospheric density fluctuations, J. Geophys. Res., 97, 20385, https://doi.org/10.1029/92JD01916, 1992.

Lübken, F.-J., Giebeler, J., Blix, T., Thrane, E., Singer, W., and Bremer, J.: In-situ measurement of the Schmidt number within a PMSE layer, Geophys. Res. Lett., 21, 1651-1654, https://doi.org/10.1029/94GL01355, 1994.

Lübken, F. J., Rapp, M., Blix, T., and Thrane, E.: Microphysical and turbulent measurements of the Schmidt number in the vicinity of polar mesosphere summer echoes, Geophys. Res. Lett., 25, 893896, https://doi.org/10.1029/98GL50479, 1998.

Lübken, F.-J., Strelnikov, B., Rapp, M., Singer, W., Latteck, R., Brattli, A., Hoppe, U.-P., and Friedrich, M.: The thermal and dynamical state of the atmosphere during polar mesosphere winter echoes, Atmos. Chem. Phys., 6, 13-24, https://doi.org/10.5194/acp-6-13-2006, 2006.

Lübken, F. J., Singer, W., Latteck, R., and Strelnikova, I.: Radar measurements of turbulence, electron densities, and absolute reflectivities during polar mesosphere winter echoes (PMWE), Adv. Space Res., 40, 758-764, https://doi.org/10.1016/j.asr.2007.01.015, 2007.

Lynch, K. A.: Multiple sounding rocket observations of charged dust in the polar winter mesosphere, J. Geophys. Res., 110, A03302, https://doi.org/10.1029/2004JA010502, 2005.

Megner, L., Rapp, M., and Gumbel, J.: Distribution of meteoric smoke - sensitivity to microphysical properties and atmospheric conditions, Atmos. Chem. Phys., 6, 4415-4426, https://doi.org/10.5194/acp-6-4415-2006, 2006.

Natanson, G. L.: On the theory of the charging of microscopic aerosol particles as a result of capture of gas ions., Sov. Phys.Tech. Phys. (Engl. Transl.), 5, 538-551, 1960.

Plane, J. M., Saunders, R. W., Hedin, J., Stegman, J., Khaplanov, M., Gumbel, J., Lynch, K. A., Bracikowski, P. J., Gelinas, L. J., Friedrich, M., Blindheim, S., Gausa, M., and Williams, B. P.: A combined rocket-borne and groundbased study of the sodium layer and charged dust in the upper mesosphere, J. Atmos. Sol.-Terr. Phy., 118, 151-160, https://doi.org/10.1016/j.jastp.2013.11.008, 2014.

Plane, J. M. C., Feng, W., and Dawkins, E. C. M.: The mesosphere and metals: chemistry and changes, Chem. Rev., 115, 4497-541, https://doi.org/10.1021/cr500501m, 2015.

Rapp, M. and Lübken, F.-J.: Modelling of particle charging in the polar summer mesosphere: Part 1 - General results, J. Atmos. Sol.-Terr. Phy., 63, 759-770, https://doi.org/10.1016/S13646826(01)00006-2, 2001.

Rapp, M. and Lübken, F.-J.: Polar mesosphere summer echoes (PMSE): Review of observations and current understanding, At- 
mos. Chem. Phys., 4, 2601-2633, https://doi.org/10.5194/acp-42601-2004, 2004.

Rapp, M., Lübken, F.-J., and Blix, T. A.: Small scale density variations of electrons and charged particles in the vicinity of polar mesosphere summer echoes, Atmos. Chem. Phys., 3, 1399-1407, https://doi.org/10.5194/acp-3-1399-2003, 2003.

Rapp, M., Hedin, J., Strelnikova, I., Friedrich, M., Gumbel, J., and Lübken, F.-J.: Observations of positively charged nanoparticles in the nighttime polar mesosphere, Geophys. Res. Lett., 32, L23821, https://doi.org/10.1029/2005GL024676, 2005.

Rapp, M., Strelnikova, I., and Gumbel, J.: Meteoric smoke particles: Evidence from rocket and radar techniques, Adv. Space Res., 40, 809-817, https://doi.org/10.1016/j.asr.2006.11.021, 2007.

Rapp, M., Strelnikova, I., Latteck, R., Hoffmann, P., Hoppe, U.P., Häggström, I., and Rietveld, M. T.: Polar mesosphere summer echoes (PMSE) studied at Bragg wavelengths of $2.8 \mathrm{~m}$, $67 \mathrm{~cm}$, and $16 \mathrm{~cm}$, J. Atmos. Sol.-Terr. Phy., 70, 947-961, https://doi.org/10.1016/j.jastp.2007.11.005, 2008.

Rapp, M., Strelnikova, I., Strelnikov, B., Hoffmann, P., Friedrich, M., Gumbel, J., Megner, L., Hoppe, U.-P., Robertson, S., Knappmiller, S., Wolff, M., and Marsh, D. R.: Rocket-borne in situ measurements of meteor smoke: Charging properties and implications for seasonal variation, J. Geophys. Res., 115, D00I16, https://doi.org/10.1029/2009JD012725, 2010.

Rapp, M., Latteck, R., Stober, G., Hoffmann, P., Singer, W., and Zecha, M.: First three-dimensional observations of polar mesosphere winter echoes: Resolving spacetime ambiguity, J. Geophys. Res.-Space, 116, A11307, https://doi.org/10.1029/2011JA016858, 2011.

Rapp, M., Plane, J. M. C., Strelnikov, B., Stober, G., Ernst, S., Hedin, J., Friedrich, M., and Hoppe, U.-P.: In situ observations of meteor smoke particles (MSP) during the Geminids 2010: constraints on MSP size, work function and composition, Ann. Geophys., 30, 1661-1673, https://doi.org/10.5194/angeo30-1661-2012, 2012.

Robertson, S., Dickson, S., Horányi, M., Sternovsky, Z., Friedrich, M., Janches, D., Megner, L., and Williams, B.: Detection of meteoric smoke particles in the mesosphere by a rocket-borne mass spectrometer, J. Atmos. Sol.-Terr. Phy., 118, 161-179, https://doi.org/10.1016/j.jastp.2013.07.007, 2014.

Rosinski, J. and Snow, R. H.: Secondary particulate matter from meteor vapors, J. Meteorol., https://doi.org/10.1175/15200469(1961)018<0736:SPMFMV>2.0.CO;2, 1961.

Rusch, D., Thomas, G., Merkel, A., Olivero, J., Chandran, A., Lumpe, J., Carstans, J., Randall, C., Bailey, S., and Russell, J.: Large ice particles associated with small ice water content observed by AIM CIPS imagery of polar mesospheric clouds: Evidence for microphysical coupling with small-scale dynamics, https://doi.org/10.1016/j.jastp.2016.04.018, 2016.

Scanlon, T. J., Roohi, E., White, C., Darbandi, M., and Reese, J. M.: An open source, parallel DSMC code for rarefied gas flows in arbitrary geometries, Computers and Fluids, 39, 2078-2089, https://doi.org/10.1016/j.compfluid.2010.07.014, 2010.

Scientific Instrument Services: SIMION, available at: http://simion. com/ (last access: 25 May 2017), 2013.

Staszak, T.: Aerodynamische Simulationen von raketengetragenen in-situ Dichtemessungen in der MLT-region, PhD thesis, University of Rostock, Rostock, 2015.
Stebel, K., Blum, U., Fricke, K.-H., Kirkwood, S., Mitchell, N., and Osepian, A.: Joint radar/lidar observations of possible aerosol layers in the winter mesosphere, J. Atmos. Sol.-Terr. Phy., 66, 957-970, https://doi.org/10.1016/j.jastp.2004.03.008, 2004.

Sternovsky, Z.: Potential distribution around sounding rockets in mesospheric layers with charged aerosol particles, Geophys. Res. Lett., 31, L22101, https://doi.org/10.1029/2004GL020949, 2004.

Strelnikov, B. and Rapp, M.: In Situ Measurements of Small-Scale Structures in Neutrals and Charged Aerosols, in: Aeronomy of the Earth's Atmosphere and Ionosphere, 83-91, Springer Netherlands, Dordrecht, https://doi.org/10.1007/978-94-007-0326-1_6, 2011.

Strelnikov, B., Rapp, M., and Lübken, F.-J.: A new technique for the analysis of neutral air density fluctuations measured in situ in the middle atmosphere, Geophys. Res. Lett., 30, 2052, https://doi.org/10.1029/2003GL018271, 2003.

Strelnikov, B., Rapp, M., Strelnikova, I., Engler, N., and Latteck, R.: Small-scale structures in neutrals and charged aerosol particles as observed during the ECOMA/MASS rocket campaign, Ann. Geophys., 27, 1449-1456, https://doi.org/10.5194/angeo27-1449-2009, 2009.

Strelnikov, B., Szewczyk, A., and Rapp, M.: In-situ measurements of small-scale structures in neutrals and plasma species during ECOMA-2010, in: EGU General Assembly Conference Abstracts, edited by: Abbasi, A. and Giesen, N., vol. 14 of EGU General Assembly Conference Abstracts, p. 11861, 2012.

Strelnikov, B., Rapp, M., and Lübken, F.-J.: In-situ density measurements in the mesosphere/lower thermosphere region with the TOTAL and CONE instruments, in: An Introduction to Space Instrumentation, edited by: Oyama, K., Terra Publishers, https://doi.org/10.5047/aisi.001, 2013.

Strelnikov, B., Szewczyk, A., Strelnikova, I., Latteck, R., Baumgarten, G., Lübken, F.-J., Rapp, M., Fasoulas, S., Löhle, S., Eberhart, M., Hoppe, U.-P., Dunker, T., Friedrich, M., Hedin, J., Khaplanov, M., Gumbel, J., and Barjatya, A.: Spatial and temporal variability in MLT turbulence inferred from in situ and ground-based observations during the WADIS1 sounding rocket campaign, Ann. Geophys., 35, 547-565, https://doi.org/10.5194/angeo-35-547-2017, 2017.

Strelnikova, I. and Rapp, M.: Statistical characteristics of PMWE observations by the EISCAT VHF radar, Ann. Geophys., 31, 359-375, https://doi.org/10.5194/angeo-31-359-2013, 2013.

Strelnikova, I., Rapp, M., Raizada, S., and Sulzer, M.: Meteor smoke particle properties derived from Arecibo incoherent scatter radar observations, Geophys. Res. Lett., 34, L15815, https://doi.org/10.1029/2007GL030635, 2007.

Strelnikova, I., Rapp, M., Strelnikov, B., Baumgarten, G., Brattli, A., Svenes, K., Hoppe, U.-P., Friedrich, M., Gumbel, J., and Williams, B. P.: Measurements of meteor smoke particles during the ECOMA-2006 campaign: 2. Results, J. Atmos. Sol.-Terr. Phy., 71, 486-496, 2009.

Thomas, L. and Bowman, M. R.: Model studies of the D-region negative-ion composition during day-time and night-time, J. Atmos. Terr. Phys., 47, 547-556, https://doi.org/10.1016/00219169(85)90037-6, 1985.

Torrence, C. and Compo, G.: A Practical Guide to Wavelet Analysis, B. Am. Meteorol. Soc., 79, 61-78, 1998.

von Cossart, G., Fiedler, J., and von Zahn, U.: Size distributions of NLC particles as determined from 3-color observations of 
NLC by ground-based lidar, Geophys. Res. Lett., 26, 1513-1516, https://doi.org/10.1029/1999GL900226, 1999.

Vondrak, T., Plane, J. M. C., Broadley, S., and Janches, D.: A chemical model of meteoric ablation, Atmos. Chem. Phys., 8, 70157031, https://doi.org/10.5194/acp-8-7015-2008, 2008.
Yamamoto, M.: A Moment Method of the Log-Normal Size Distribution with the Critical Size Limit in the FreeMolecular Regime, Aerosol Sci. Tech., 48, 725-737, https://doi.org/10.1080/02786826.2014.922161, 2014. 